\title{
Simulations of organic aerosol concentrations in Mexico City using the WRF-CHEM model during the MCMA-2006/MILAGRO campaign
}

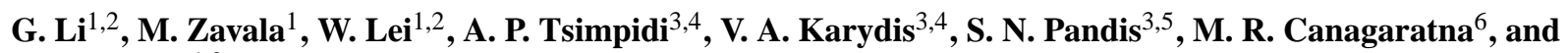 \\ L. T. Molina ${ }^{1,2}$ \\ ${ }^{1}$ Molina Center for the Energy and the Environment, La Jolla, CA, USA \\ ${ }^{2}$ Massachusetts Institute of Technology, Cambridge, MA, USA \\ ${ }^{3}$ Department of Chemical Engineering, University of Patras, Patras, Greece \\ ${ }^{4}$ Institute of Chemical Engineering and High Temperature Chemical Processes, Foundation of Research and Technology \\ Hellas, Patras, Greece \\ ${ }^{5}$ Department of Chemical Engineering, Carnegie Mellon University, Pittsburgh, PA, USA \\ ${ }^{6}$ Aerodyne Research Inc, Billerica, MA, USA
}

Received: 18 October 2010 - Published in Atmos. Chem. Phys. Discuss.: 1 December 2010

Revised: 1 April 2011 - Accepted: 17 April 2011 - Published: 27 April 2011

\begin{abstract}
Organic aerosol concentrations are simulated using the WRF-CHEM model in Mexico City during the period from 24 to 29 March in association with the MILAGRO2006 campaign. Two approaches are employed to predict the variation and spatial distribution of the organic aerosol concentrations: (1) a traditional 2-product secondary organic aerosol (SOA) model with non-volatile primary organic aerosols (POA); (2) a non-traditional SOA model including the volatility basis-set modeling method in which primary organic components are assumed to be semi-volatile and photochemically reactive and are distributed in logarithmically spaced volatility bins. The MCMA (Mexico City Metropolitan Area) 2006 official emission inventory is used in simulations and the POA emissions are modified and distributed by volatility based on dilution experiments for the non-traditional SOA model. The model results are compared to the Aerosol Mass Spectrometry (AMS) observations analyzed using the Positive Matrix Factorization (PMF) technique at an urban background site (T0) and a suburban background site (T1) in Mexico City. The traditional SOA model frequently underestimates the observed POA concentrations during rush hours and overestimates the observations in the rest of the time in the city. The model also substantially underestimates the observed SOA concentrations, particularly during daytime, and only produces $21 \%$ and $25 \%$ of the ob-
\end{abstract}

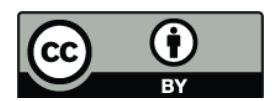

Correspondence to: $\mathrm{G}$. $\mathrm{Li}$ (lgh@mce2.org) served SOA mass in the suburban and urban area, respectively. The non-traditional SOA model performs well in simulating the POA variation, but still overestimates during daytime in the urban area. The SOA simulations are significantly improved in the non-traditional SOA model compared to the traditional SOA model and the SOA production is increased by more than $100 \%$ in the city. However, the underestimation during daytime is still salient in the urban area and the non-traditional model also fails to reproduce the high level of SOA concentrations in the suburban area. In the nontraditional SOA model, the aging process of primary organic components considerably decreases the $\mathrm{OH}$ levels in simulations and further impacts the SOA formation. If the aging process in the non-traditional model does not have feedback on the $\mathrm{OH}$ in the gas-phase chemistry, the SOA production is enhanced by more than $10 \%$ compared to the simulations with the $\mathrm{OH}$ feedback during daytime, and the gap between the simulations and observations in the urban area is around $3 \mu \mathrm{g} \mathrm{m}^{-3}$ or $20 \%$ on average during late morning and early afternoon, within the uncertainty from the AMS measurements and PMF analysis. In addition, glyoxal and methylglyoxal can contribute up to approximately $10 \%$ of the observed SOA mass in the urban area and $4 \%$ in the suburban area. Including the non-OH feedback and the contribution of glyoxal and methylglyoxal, the non-traditional SOA model can explain up to $83 \%$ of the observed SOA in the urban area, and the underestimation during late morning and early afternoon is reduced to $0.9 \mu \mathrm{g} \mathrm{m}^{-3}$ or $6 \%$ on average. Considering

Published by Copernicus Publications on behalf of the European Geosciences Union. 
the uncertainties from measurements, emissions, meteorological conditions, aging of semi-volatile and intermediate volatile organic compounds, and contributions from background transport, the non-traditional SOA model is capable of closing the gap in SOA mass between measurements and models.

\section{Introduction}

Atmospheric aerosols influence the radiative balance in Earth's atmosphere and play a central role in climate, directly by scattering or absorbing a fraction of the incoming solar radiation to cool or warm the atmosphere, and indirectly via their roles as cloud condensation nuclei $(\mathrm{CCN})$ and ice nuclei (IN), by modifying optical properties and lifetime of clouds (e.g., Penner et al., 2001; R. Zhang et al., 2007). Additionally, high levels of particulate matter are associated with adverse human effects, including increased morbidity and mortality arising from altered respiratory and cardiovascular function (e.g., Pope and Dockery, 2006; Harrison and Yin, 2000; Davidson et al., 2005).

Organic aerosols (OA) account for $20-90 \%$ of the total fine particulate mass in the atmosphere (Q. Zhang et al., 2007). Generally, OA is categorized into two types: primary OA (POA) that is directly emitted into the atmosphere in particulate form, and secondary OA (SOA) which is formed from chemically processed gaseous organic precursors. However, due to the involvement of multiple volatile organic compounds (VOCs) and the complexity of atmospheric degradation processes of each VOC, there are considerable uncertainties when simulating the atmospheric oxidation products of VOCs that undergo gas-particle transfer to produce SOA. The limited understanding on the formation mechanisms, composition and properties of SOA has constituted the greatest uncertainty in OA prediction in climate and air quality models (Hallquist et al., 2009).

Traditionally, the SOA formation from VOCs and oxidants is predicted using semi-empirical 2-product parameterizations in which saturation vapor pressures and mass-based stoichiometric yield coefficients of SVOCs (Semi-Volatile Organic Compounds or Semi-VOCs) are obtained from either smog chamber experiments or from published estimates (Pankow, 1994; Odum et al., 1996). Recent studies have demonstrated that the traditional 2-product approach significantly underestimates the measured SOA mass concentrations in urban and remote regions (e.g., de Gouw et al., 2009; Zhang et al., 2006). For example, during the MCMA-2003 field study in Mexico City (Molina et al., 2007), Volkamer et al. (2006) have reported much larger observed amounts of SOA formed from reactive anthropogenic VOCs than the estimation from a SOA model based on empirical parameterization of chamber experiments. Dzepina et al. (2009) have suggested that traditional SOA precursors (mainly aromatics) fail to produce enough SOA to match observations. Furthermore, Hodzic et al. (2009) have estimated that less than $15 \%$ of the observed SOA in Mexico City can be explained by the traditional mechanism based on oxidation of anthropogenic precursors.

Recent advances in the understanding of SOA formation have provided opportunities to close the gap between measurements and SOA models. Recent smog chamber experiments have shown more aerosol formation than found previously (Ng et al., 2006, 2007; Hildebrandt et al., 2009). Robinson et al. (2007) have suggested that most primary organic-particulate emissions are semi-volatile and hence partially evaporate to act as SOA precursors. Grieshop et al. (2009) have proposed a variation of the mechanism of Robinson et al. (2007) based on the evolution of chamber SOA from wood smoke that has a similar distribution of semi-volatile species as diesel emissions. Additionally, oligomers and organosulfates have been identified recently in SOA formed in chambers and in the atmosphere, indicating that the SOA formation is also influenced by propensity of degradation products to undergo further reactions in the condensed phase (Hallquist et al., 2009). Volkamer et al. (2007) have pointed out that glyoxal, a very volatile species, can also be a source of SOA. Based on the new proposed SOA formation mechanisms mentioned above, Dzepina et al. (2009) have successfully closed the gap in SOA mass between measurements and simulations in Mexico City using a photochemical box model. Tsimpidi et al. (2010) have evaluated the effects of the semi-volatile nature of primary organic emissions and photochemical aging of primary and secondary organics on OA levels in MCMA using a modified 3-D chemical transport model (PMCAMx) and the results are encouraging when comparing to the measurements. Hodzic et al. (2010) have estimated the contribution of semivolatile and intermediate VOCs to the SOA formation in Mexico City with a 3-D regional air quality model; they reported that semi-volatile and intermediate VOCs from anthropogenic sources and biogenic burning can explain 40$60 \%$ of the measured SOA at the surface during day time. Jimenez et al. (2009) have presented a unifying OA evolution model framework in which OA and OA precursor gases become increasingly oxidized, less volatile, more hygroscopic, leading to formation of oxygenated organic aerosol (OOA).

During the MCMA (Mexico City Metropolitan Area)2006 field campaign as part of the MILAGRO (Megacity Initiative: Local and Global Research Observations) project conducted in March 2006, an extensive data set has been obtained, including highly time-resolved ambient gas phase species and aerosols (Molina et al., 2010). The comprehensive data set provides a unique opportunity to evaluate the SOA formation from recently proposed SOA formation mechanisms in the polluted urban atmosphere of the MCMA (Molina and Molina, 2002). The purpose of the present study is to evaluate the performance of recently suggested SOA formation mechanisms and the relative importance of 
different mechanisms using the WRF-CHEM model based on the measurements taken during MCMA-2006. The WRFCHEM model and the model configuration are described in Sect. 2. Results of the modeling experiments and comparisons are presented in Sect. 3, and the Conclusions are given in Sect. 4.

\section{Model description}

\subsection{WRF-CHEM model}

The version of the WRF-CHEM model used in the present study was developed by Li et al. (2010) at the Molina Center for Energy and the Environment, with a new flexible gas phase chemical module that can be utilized in different chemical mechanisms, including CB-IV, RADM2, and SAPRC. The gas-phase chemistry differential equations are solved by an Euler backward Gauss-Seidel iterative technique. The short-lived species, such as $\mathrm{OH}$ and $\mathrm{O}\left({ }^{1} \mathrm{D}\right)$, are assumed to be in steady state. The solution is iterated until all species are within $0.1 \%$ of their previous iterative values. For the aerosol simulations, the CMAQ (version 4.6) aerosol module developed by US EPA, which is designed to be an efficient and economical depiction of aerosol dynamics in the atmosphere (Binkowski and Roselle, 2003), is implemented in the WRF-CHEM model. In this aerosol module, the particle size distribution is represented as the superposition of three lognormal sub-distributions called modes. The processes of coagulation, particle growth by the addition of mass, and new particle formation are included. The new particle production rate due to binary nucleation of $\mathrm{H}_{2} \mathrm{SO}_{4}$ and water vapor is parameterized following the work of Kulmala et al. (1998). The new particles are assumed to be $2.0 \mathrm{~nm}$ in diameter. More recent studies (Zhang et al., 2004; Paasonen et al., 2010) have suggested that organic vapors may be involved in the nucleation process. However, the organic mass that may participate in the formation of the fresh nuclei is under all conditions negligible compared to the organic aerosol concentration in this polluted environment. On the other hand, the contribution of the organics to the growth of the new particles is simulated by our model. In addition, the wet deposition also follows the method used in CMAQ. Surface deposition of chemical species is parameterized following Wesely (1989). The photolysis rates are calculated using the Fast Tropospheric Ultraviolet and Visible (FTUV) Radiation Model (Tie et al., 2003; Li et al., 2005).

Li et al. (2010) have found that HONO sources play an important role in the early morning photochemistry and the formation of secondary aerosols via photolysis to form $\mathrm{OH}$. The HONO sources suggested by Li et al. (2010) have been considered in this study to enhance the $\mathrm{OH}$ concentration. In addition, two additional $\mathrm{OH}$ sources are also incorporated in the WRF-CHEM model. The first one is the reaction of excited $\mathrm{NO}_{2}$ with $\mathrm{H}_{2} \mathrm{O}$ (Li et al., 2008):

$$
\begin{aligned}
& \mathrm{NO}_{2}+h v \rightarrow \mathrm{NO}_{2}^{*} \\
& \mathrm{NO}_{2}^{*}+\mathrm{O}_{2} \rightarrow \mathrm{NO}_{2}+\mathrm{O}_{2} \\
& \mathrm{NO}_{2}^{*}+\mathrm{N}_{2} \rightarrow \mathrm{NO}_{2}+\mathrm{N}_{2} \\
& \mathrm{NO}_{2}^{*}+\mathrm{H}_{2} \mathrm{O} \rightarrow \mathrm{NO}_{2}+\mathrm{H}_{2} \mathrm{O} \\
& \mathrm{NO}_{2}^{*}+\mathrm{H}_{2} \mathrm{O} \rightarrow \mathrm{OH}+\mathrm{HONO}
\end{aligned}
$$

The rate constants used are $k_{2}=3.3 \times 10^{-11}, k_{3}=2.7 \times$ $10^{-11}, \quad k_{4 \mathrm{a}}=1.7 \times 10^{-10}$, and $k_{4 \mathrm{~b}}=1.7 \times 10^{-13} \mathrm{~cm}^{3}$ molec $^{-1} \mathrm{~s}^{-1}$. Time-resolved photolysis frequencies for R1 are calculated using $\mathrm{NO}_{2}$ absorption cross sections, quantum yields for the production of excited molecules of $\mathrm{NO}_{2}$ and values of the actinic flux (320-645 nm). Absorption cross sections and quantum yields are taken from the FTUV model (Tie et al., 2003). The second $\mathrm{OH}$ source is peroxy radical reactions such as:

$\mathrm{RO}_{2}+\mathrm{HO}_{2} \rightarrow \alpha \mathrm{OH}$

where $\alpha$ is assumed to be 0.5 (Lelieveld et al., 2008).

\subsection{Secondary organic aerosol models}

Two types of SOA models are considered in the WRFCHEM model: a traditional 2-product SOA model (T2-SOA model) adopted from CMAQ (Binkowski and Roselle, 2003), and a non-traditional SOA model (NT-SOA model) developed by Tsimpidi et al. (2010).

\subsubsection{T2-SOA model}

In the T2-SOA model, the SOA concentrations are simulated from the oxidation of six lumped organic species: alkanes, alkenes, cresol, high-yield aromatics, low-yield aromatics, and monoterpenes. Ten semi-volatile organic compounds (SVOC) are produced via these reactions - two each for olefins, monoterpenes, and aromatics, and one each for alkanes and cresol.

$\mathrm{POG}+$ oxidant $\rightarrow \alpha_{1} \mathrm{SVOC}_{1}+\alpha_{\mathrm{S}} \mathrm{VOC}_{2}$

The oxidants mainly include the $\mathrm{OH}$ radical, the nitrate radical $\mathrm{NO}_{3}$, and $\mathrm{O}_{3}$. The saturation vapor pressures and massbased stoichiometric yield coefficients $\left(\alpha_{i}\right)$ of SVOCs are obtained from either smog chamber experiments or from published estimates in cases where smog chamber data are unavailable. The SOA is calculated using the method developed by Schell et al. (2001), which was based on the absorptive partitioning model of Pankow (1994) that was extended by Odum et al. (1996). When the organic gas/aerosol equilibrium has been established, gas and aerosol-phase concentrations of each SVOC are calculated iteratively using a globally convergent variation of Newton's method. 


\subsubsection{NT-SOA model}

In the NT-SOA model, the volatility basis-set approach (Lane et al., 2008a) is used to consider the SOA formation, assuming that primary organic components are semi-volatile and photochemically reactive and are distributed in logarithmically spaced volatility bins. The partitioning of semivolatile organic species is calculated using the algorithm suggested by Koo et al. (2003), in which the bulk gas and particle phases are in equilibrium and all condensable organics form a pseudo-ideal solution (Odum et al., 1996). Nine surrogate species with saturation concentrations from $10^{-2}$ to $10^{6} \mu \mathrm{g} \mathrm{m}^{-3}$ at room temperature are used for the POA components following the approach of Shrivastava et al. (2008).

Based on the volatility basis-set approach, the traditional SOA formation from each anthropogenic or biogenic precursor is predicted using four SVOCs whose effective saturation concentrations at $298 \mathrm{~K}$ are $1,10,100$, and $1000 \mu \mathrm{g} \mathrm{m}^{-3}$, respectively, instead of the traditional 2-product parameterization. In the base case, we assume that these four surrogate SVOCs species do not react further with $\mathrm{OH}$ radicals to reduce the volatility. Tsimpidi et al. (2010) and Murphy and Pandis (2009) have assumed that these first generation products continue to react and age. The importance of this anthropogenic SOA aging process will be explored in a sensitivity test in a subsequent section. The anthropogenic aerosol yields have been updated based on laboratory results from recent smog-chamber experiments $(\mathrm{Ng}$ et al., 2006; Hildebrandt et al., 2009) and are $\mathrm{NO}_{\mathrm{x}}$-dependent (Lane et al., 2008b). Under low- $\mathrm{NO}_{\mathrm{x}}$ conditions, $\mathrm{RO}_{2}$ radicals react with other peroxy radicals to form a distribution of products with lower volatilities, resulting in higher SOA yields. However, when the $\mathrm{NO}_{\mathrm{x}}$ concentrations are high, the SOA yields are lower because $\mathrm{RO}_{2}$ predominantly reacts with $\mathrm{NO}$ and the products distribution is dominated by aldehydes, ketones, and nitrates. However, the $\mathrm{NO}_{\mathrm{x}}$-dependent SOA yields from biogenic precursors may be more complicated and variable. Isoprene SOA yields increase with increasing $\mathrm{VOC} / \mathrm{NO}_{\mathrm{x}}$ ratio, but after $\mathrm{VOC} / \mathrm{NO}_{\mathrm{x}}$ exceeds about 1 they start decreasing (Hoyle et al., 2011). The monoterpene SOA yields have a similar behavior although a higher $\mathrm{VOC} / \mathrm{NO}_{\mathrm{x}}$ ratio is reached before the yields start decreasing. SOA yields during the oxidation of sesquiterpenes on the other hand increase as the $\mathrm{NO}_{\mathrm{x}}$ concentrations increase (Hoyle et al., 2011). In the present study, $\mathrm{NO}_{\mathrm{x}}$-dependent SOA yields from biogenic precursors are calculated as those from anthropogenic precursors.

In this new approach, all primary species are treated as chemically reactive. Primary organic gases (POG), emitted or formed due to evaporation of POA in the atmosphere (Robinson et al., 2007), are assumed to react with $\mathrm{OH}$ radicals to reduce their volatility and hence to partition between gas and particle phase forming SOA. Intermediate volatile organic compounds (IVOCs), which are co-emitted with the POA but are never in the particle phase during the emission process, are also oxidized by $\mathrm{OH}$ to form SOA. Based on their chamber studies of diesel exhaust, Robinson et al. (2007) have assumed that POG and IVOC react with $\mathrm{OH}$ with $k_{\mathrm{OH}}=4 \times 10^{-11} \mathrm{~cm}^{3}$ molec $^{-1} \mathrm{~s}^{-1}$ (Atkinson and Arey, 2003). Each reaction is assumed to reduce the volatility of the vapor material by an order of magnitude (e.g., shifting material from a $C^{*}$ of 100 to $10 \mu \mathrm{g} \mathrm{m}^{-3}$ ), with a small net increase in mass $(7.5 \%)$ to account for added oxygen. Although it is known that gas-phase organic reactions can lead to bond scission (Kroll and Seinfeld, 2008), this mechanism assumes that no VOCs of higher volatility, $\mathrm{CO}$, or $\mathrm{CO}_{2}$ are formed, which if taken into account would reduce the amount of SOA formed. Another structural uncertainty of the aging mechanism is the lack of particle-phase accretion reactions (e.g. Barsanti and Pankow, 2005), which if included would increase the amount of model SOA produced. It is worthy to note that the aging process is still very uncertain. Grieshop et al. (2009) have proposed a new mechanism, in which every generation of oxidation decreases the saturation concentration $\left(C^{*}\right)$ of the products by two orders of magnitude per oxidation step and the mass increase per oxidation step is $40 \%$ but the oxidation rates with $\mathrm{OH}$ is decreased to $2 \times 10^{-11} \mathrm{~cm}^{3} \mathrm{molec}^{-1} \mathrm{~s}^{-1}$. The base case reaction scheme is represented by the reactions below based on Robinson et al. (2007):

$$
\begin{aligned}
& \operatorname{POA}_{i(p)} \leftrightarrow \mathrm{POG}_{i(g)} \\
& \mathrm{POG}_{i(g)}+\mathrm{OH} \rightarrow 1.075 \mathrm{OPOG}_{i-1(g)} \\
& \mathrm{OPOG}_{i-1(g)} \leftrightarrow \mathrm{SOA}_{(p)} \\
& \mathrm{IVOC}_{i(g)}+\mathrm{OH} \rightarrow 1.075 \mathrm{IVOC}_{i-1(g)} \\
& \mathrm{IVOC}_{i-1(g)} \leftrightarrow \mathrm{SOA}_{(p)} \\
& \operatorname{VOC}_{(g)}+\mathrm{OH} \rightarrow \sum_{i=1}^{4} a_{i} \operatorname{SVOC}_{i(g)} \\
& \operatorname{SVOC}_{i(g)} \leftrightarrow \mathrm{SOA}_{(p)}
\end{aligned}
$$

where $i$ is the corresponding volatility bin and OPOG represents the oxidized POG. Detailed description about the volatility basis-set approach can be found in Tsimpidi et al. (2010). Furthermore, when the volatility basisset approach is used in simulations, the POA emissions are redistributed following the base case suggested by Tsimpidi et al. (2010). The total amount of material $(\mathrm{POA}+\mathrm{SVOC}+\mathrm{IVOC})$ introduced in the NT-SOA model is 7.5 times the particle-phase POA emissions. Detailed description about the SOA models and the emission modification for the NT-SOA model can be found in the Supplement (SI). 


\subsection{Model configuration}

A six-day episode from 24 to 29 March 2006 is selected in the present study, including a typical " $\mathrm{O}_{3}$-Convection South" condition (24-26 March) and "O ${ }_{3}$-Convection North" condition (27-29 March) in Mexico City (de Foy et al., 2008). $\mathrm{O}_{3}$ convection South occurs when there is a weak northerly wind component aloft with rain in the southern part of the Mexico City basin. $\mathrm{O}_{3}$-convection North occurs when there is a weak southerly wind component aloft with a gap flow and rain in the northern part of the basin. The WRF-CHEM model is configured with grid spacing of $3 \mathrm{~km}(99 \times 99$ grid points) centered at $19.538^{\circ} \mathrm{N}$ and $99^{\circ} \mathrm{E}$ (Fig. 1). Thirty-five vertical levels are used in a stretched vertical grid with spacing ranging from $50 \mathrm{~m}$ near the surface, to $500 \mathrm{~m}$ at $2.5 \mathrm{~km}$ a.g.l. and $1 \mathrm{~km}$ above $14 \mathrm{~km}$. The modeling system employs the Lin microphysics scheme (Lin et al., 1983), a sophisticated one that includes ice, snow and graupel processes, suitable for real-data high-resolution simulations. The PBL scheme used is the Yonsei University (YSU) scheme (Noh et al., 2001), which includes non-local-K mixing in the dry convective boundary layer, vertical diffusion based on the Richardson number in the free atmosphere, entrainment explicitly determined, and PBL depth from the thermal profile. The Noah land-surface model (Chen and Dudhia, 2001) is used in the simulations, in which vegetation effects are included and soil temperature and soil moisture in four layers are predicted. A longwave radiation parameterization (Mlawer et al., 1997), and a shortwave radiation parameterization (Dudhia, 1989) are used for the radiation process. Meteorological initial and boundary conditions are obtained from NCEP $1^{\circ} \times 1^{\circ}$ reanalysis data. Chemical initial and boundary conditions are interpolated from MOZART 3-h output (Horowitz et al., 2003). The SOA initial conditions are set to be $0.5 \mu \mathrm{g} \mathrm{m}^{-3}$ according to the measurements on 24 March 2006 at T0 and T1 sites, and the boundary conditions in the boundary layer are set to be $1.4 \mu \mathrm{g} \mathrm{m}^{-3}$ according to the previous studies in Mexico City (Hodzic et al., 2009; Dzepina et al., 2009).

The emission inventory (EI) used in the present study is based on the 2006 official EI for the MCMA and adjusted according to observations, as described in Song et al. (2010). The emissions of the lumped species $\mathrm{ARO} 2$ are not adjusted, as Song et al. (2010) have found that the adjusted ARO2 emissions are still probably underestimated. An anthropogenic isoprene emission source equal to $1.4 \%$ of the ethylene emissions (Borbon et al., 2001; Hodzic et al., 2009) is added to improve the isoprene simulation during rush hours. The OA emissions in the present EI do not include the contributions from biomass burning in the modeling domain. Therefore, for the evaluation of OA simulations, we have chosen the above-described six-day episode that has been reported to have less impacts from biomass burning during the MILAGRO campaign (Aiken et al., 2009).
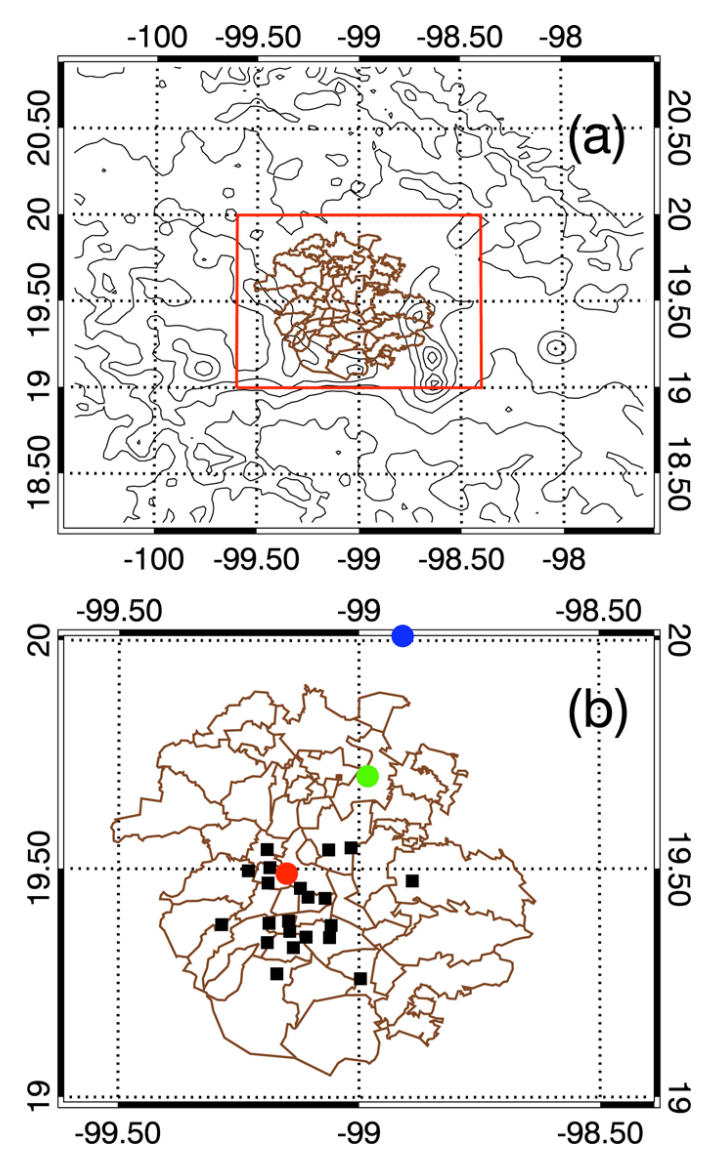

Fig. 1. WRF-CHEM simulation domain. Black squares represent the RAMA (Mexico City Ambient Air Monitoring Network) sites. The red, blue, and green circles represent the T0, T1, and T2 supersites, respectively.

\subsection{Measurements and statistical methods for comparisons}

During the MCMA-2006/MILAGRO Campaign, an extensive set of measurements of gas and aerosol pollutant concentrations was obtained from ground-based platforms, aircraft and satellites (Molina et al., 2010). Comparisons of surface $\mathrm{O}_{3}$ and $\mathrm{CO}$ are made using the measurements collected by the Mexico City Ambient Air Monitoring Network (RAMA). VOCs measurements at T0 from LP-DOAS and PTR-MS are used to verify the EI in Mexico City (Zheng et al., 2008; Song et al., 2010). The simulated organic aerosols in the WRF-CHEM model are compared with the AMS data analyzed using PMF at T0 and T1 (Aiken et al., 2009). The AMS OA is separated into three components: the hydrocarbon-like organic aerosol (HOA), which is a surrogate of fresh urban combustion related POA; the oxidized organic aerosol (OOA), which is interpreted as a surrogate of SOA and reacted POA; and the biomass burning organic aerosol (BBOA). The absolute uncertainty of the 
AMS concentrations is $\pm 25 \%$ and is dominated by the uncertainty in particle collection efficiency according to Jimenez et al. (2003) and DeCarlo et al. (2008), while the relative uncertainty in the separation of PMF components is of the order of $10 \%$. During the simulation period, at T0, the observed mean OOA concentration was $8.1 \mathrm{\mu g} \mathrm{m}^{-3}$; the HOA concentration was $5.8 \mu \mathrm{g} \mathrm{m}^{-3}$; and the BBOA concentrations was $0.60 \mu \mathrm{g} \mathrm{m}^{-3}$. At T1, the observed mean OOA concentration was $0.90 \mu \mathrm{g} \mathrm{m}^{-3}$; the HOA concentration was 4.8 ; and the BBOA concentration was $1.2 \mu \mathrm{g} \mathrm{m}^{-3}$.

In order to evaluate the overall performance of the WRFCHEM model in simulating gas-phase species and aerosols against measurements, the normalized mean bias (NMB), the root mean square error (RMSE), and the index of agreement (IOA) are used in the present study.

$\mathrm{NMB}=\frac{\sum_{i=1}^{N}\left(P_{i}-O_{i}\right)}{\sum_{i=1}^{N} O_{i}}$

$\mathrm{RMSE}=\left[\frac{1}{N} \sum_{i=1}^{N}\left(P_{i}-O_{i}\right)^{2}\right]^{\frac{1}{2}}$

$\mathrm{IOA}=1-\frac{\sum_{i=1}^{N}\left(P_{i}-O_{i}\right)^{2}}{\sum_{i=1}^{N}\left(\left|P_{i}-\bar{O}\right|+\left|O_{i}-\bar{O}\right|\right)^{2}}$

where $P_{i}$ and $O_{i}$ are the predicted and observed pollutant concentration, respectively. $N$ is the total number of the predictions used for comparisons, and $\bar{O}$ denotes the average of the observation. The IOA ranges from 0 to 1 , with 1 indicating perfect agreement between model and observation.

\section{Results and discussions}

\subsection{Model performance}

\subsection{1 $\mathrm{O}_{3}$ and $\mathrm{CO}$ comparisons with ambient measurements}

Simulated $\mathrm{O}_{3}$ and $\mathrm{CO}$ concentrations from the NT-SOA model are compared with the RAMA observations. Since meteorological conditions play a key role in air pollution simulations principally through determining the dispersion or accumulation of pollutant emissions (Bei et al., 2008, 2010), in Fig. 2a and b, we present the spatial distributions of calculated and observed near-surface concentrations of $\mathrm{O}_{3}$ at 14:00 and 17:00 Local Time (LT) from 24 to 29 March 2006, along with the simulated wind fields. Generally, at 14:00 LT, the predicted $\mathrm{O}_{3}$ spatial patterns agree well with the observations at the ambient monitoring sites. On 24
March, the stagnant conditions in the basin are favorable for the buildup of high $\mathrm{O}_{3}$ concentrations. The predicted $\mathrm{O}_{3}$ concentrations exceed $80 \mathrm{ppb}$ within almost the entire basin and are in good agreement with RAMA measurements. On 25 March, the noontime winds from the northwest of the basin are well organized and commence to evacuate the pollutants in the basin. The divergence of the pollutants in the basin causes the low $\mathrm{O}_{3}$ concentrations in the central part of the basin, reasonably consistent with the measurements. On 26 March, the light and disordered winds in the basin contribute to the development of high $\mathrm{O}_{3}$. The well organized northwest winds have impacted the plumes formed in the basin during noontime. During 27 to 29 March, the WRF-CHEM model successfully reproduces the movement of $\mathrm{O}_{3}$ plumes to the northwest, which are forced by the well organized south and northeast winds from outside of the basin. At 17:00 LT (Fig. 2b), on 24 and 25 March, the clean air from the northwest of the basin has been transported into the basin and the simulated $\mathrm{O}_{3}$ concentrations decrease to $40-60 \mathrm{ppb}$, comparable with the observations. However, on 26 March, the convergence in the basin keeps the $\mathrm{O}_{3}$ plume stagnant in the basin, leading to the overestimation of the observed $\mathrm{O}_{3}$ concentrations. On 27 March, the strong southern winds push the plume to the north of the basin and the model reasonably well reproduces the observed $\mathrm{O}_{3}$ distribution. On 28 and 29 March, the simulated plumes move slowly compared with the observations. For example, on 29 March, the observed plume had moved to the north of the basin, but part of the modeled plume remains stagnant in the center of the city. The spatial distributions of calculated and observed near-surface concentrations of $\mathrm{CO}$ at 14:00 and 17:00 are also shown in Fig. 2c and d, respectively. The WRF-CHEM model performs well in simulating the $\mathrm{CO}$ distribution compared with the measurements at RAMA monitoring sites.

Figure 3 shows the diurnal profiles of simulated and observed near-surface $\mathrm{O}_{3}$ and $\mathrm{CO}$ concentrations averaged over the RAMA monitoring sites. The WRF-CHEM model generally tracks the temporal variations of $\mathrm{O}_{3}$ concentrations reasonably well during daytime (Fig. 3a). The NMB and RMSE are $20 \%$ and $11 \mathrm{ppb}$, respectively, and the IOA reaches $95 \%$, indicating good agreement of $\mathrm{O}_{3}$ simulations with measurements. On 24 and 27 March, the model reproduces successfully the daytime variations of $\mathrm{O}_{3}$ concentrations. In the remaining four days, the model is capable of replicating the rapid increase of morning $\mathrm{O}_{3}$ concentrations and the falloff of afternoon $\mathrm{O}_{3}$ levels, but the overestimation of $\mathrm{O}_{3}$ concentrations still exists in the afternoon, which is attributed principally to the slow movement of the plumes. Although the low nighttime $\mathrm{O}_{3}$ concentrations due to the titration of emitted $\mathrm{NO}$ are reproduced, the nighttime simulated $\mathrm{O}_{3}$ deviates considerably from the observations, except on 26 March, because of difficulties in modeling the meteorological fields during the night, such as difficulty of adequately representing nocturnal layers and their mixing (Li et al., 2007) and the evacuation efficiency of the pollutants in the city (Zhang et 

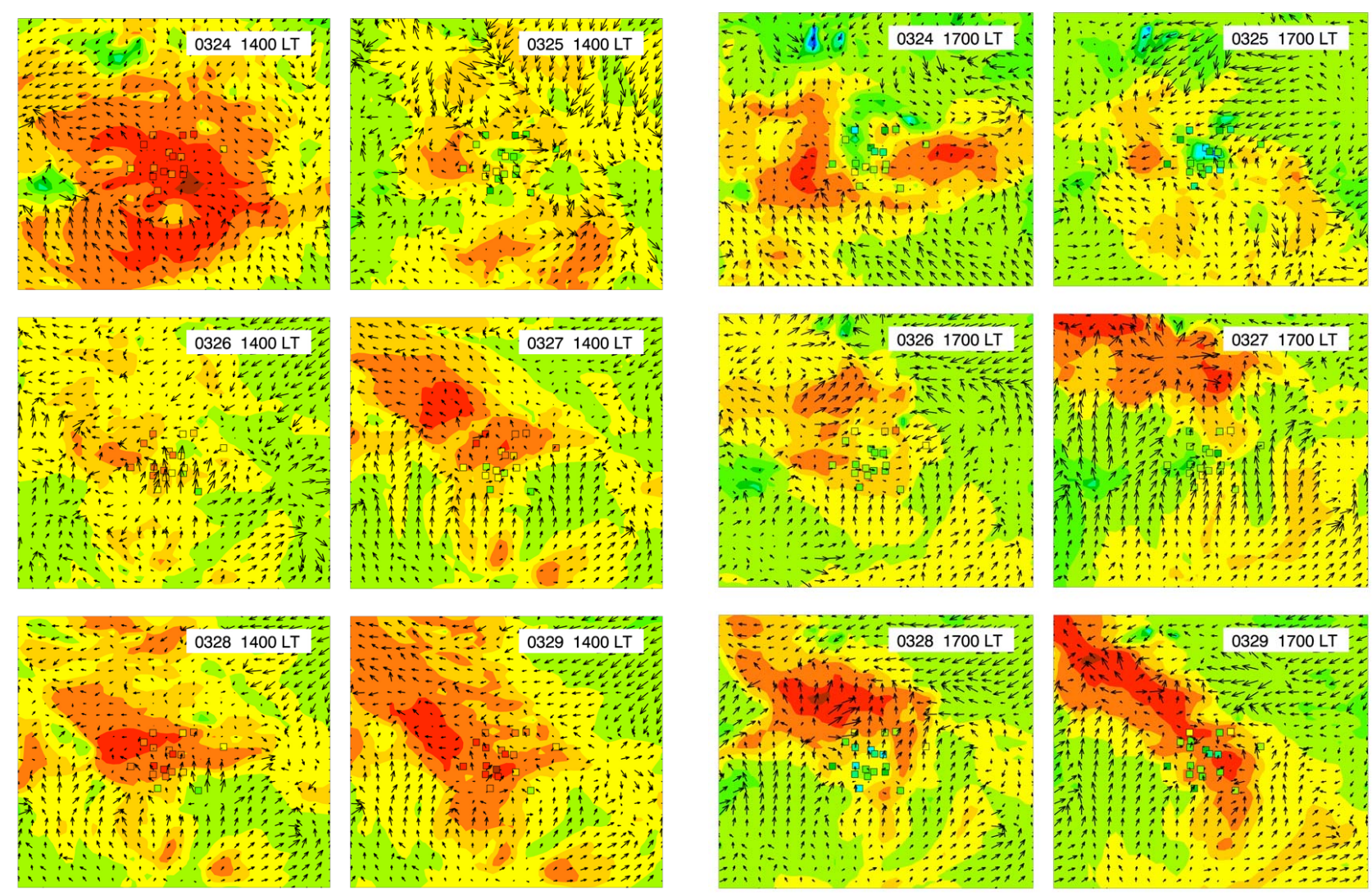

$4 \vec{m} s^{-1}$

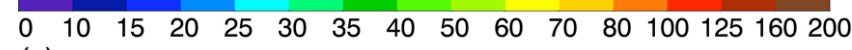

(a)

$\mathrm{O}_{3}$ Concentration (ppb)

(b)

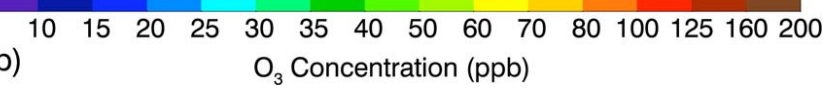

Fig. 2. Pattern comparison of simulated vs. observed $\mathrm{O}_{3}$ and $\mathrm{CO}$ at 14:00 and 17:00 LT over Mexico City during the period from 24 to 29 March 2006. Colored squares: $\mathrm{O}_{3}$ or $\mathrm{CO}$ observations; color contour: $\mathrm{O}_{3}$ or CO simulations in the NT-SOA model; black arrows: simulated surface winds.

al., 2009). During the night of 26 March, the overestimation of $\mathrm{O}_{3}$ concentrations and underestimation of $\mathrm{CO}$ concentrations are rather large due to the dominance of the air mass transported outside of Mexico City with high $\mathrm{O}_{3}$ and low $\mathrm{CO}$ concentrations. In Fig. 3b, the model follows well the variation of $\mathrm{CO}$ concentrations during daytime in general, but it frequently overestimates $\mathrm{CO}$ concentrations during nighttime, indicating either the failure of PBL simulations or inefficiency of the pollutant dispersion process or problems with the emissions during nighttime (Zhang et al., 2009). The $\mathrm{NMB}$ and RMSE are $10 \%$ and $0.5 \mathrm{ppm}$, respectively, and the IOA reduces to $84 \%$ compared to the $\mathrm{O}_{3}$ simulations. The good agreement between the long-lived predicted $\mathrm{CO}$ and the corresponding measurements suggests that the model simulates reasonably well the meteorological fields and the $\mathrm{CO}$ emissions are also reasonable during daytime.

\subsubsection{Organic aerosol simulations at $\mathrm{T} 0$ and $\mathrm{T} 1$}

Figure $4 \mathrm{a}$ and $\mathrm{b}$ show the comparison of modeled and observed total organic aerosol (TOA) diurnal profiles at T0 and T1, respectively. In general, the T2-SOA model substantially underestimates the observed TOA at T0 during daytime, with a NMB of $-31 \%$ and IOA of 0.62 (Table 1 ). The NT-SOA model improves the daytime TOA simulations at T0, particularly during rush hours, and compared to the T2-SOA model, the NMB is decreased to $-10 \%$ while the IOA increases reaching 0.82 . The underestimation of TOA in the T2-SOA and NT-SOA models is rather large at $\mathrm{T} 1$ compared to measurements, particularly during daytime and in the two models, the NMB and IOA are about $-50 \%$ and 0.50 , respectively. One of the possible reasons for the TOA underestimation at $\mathrm{T} 1$ is that the POA emissions in the present study do not include the contribution from biomass burning. Although the biomass burning is less important during the simulation 

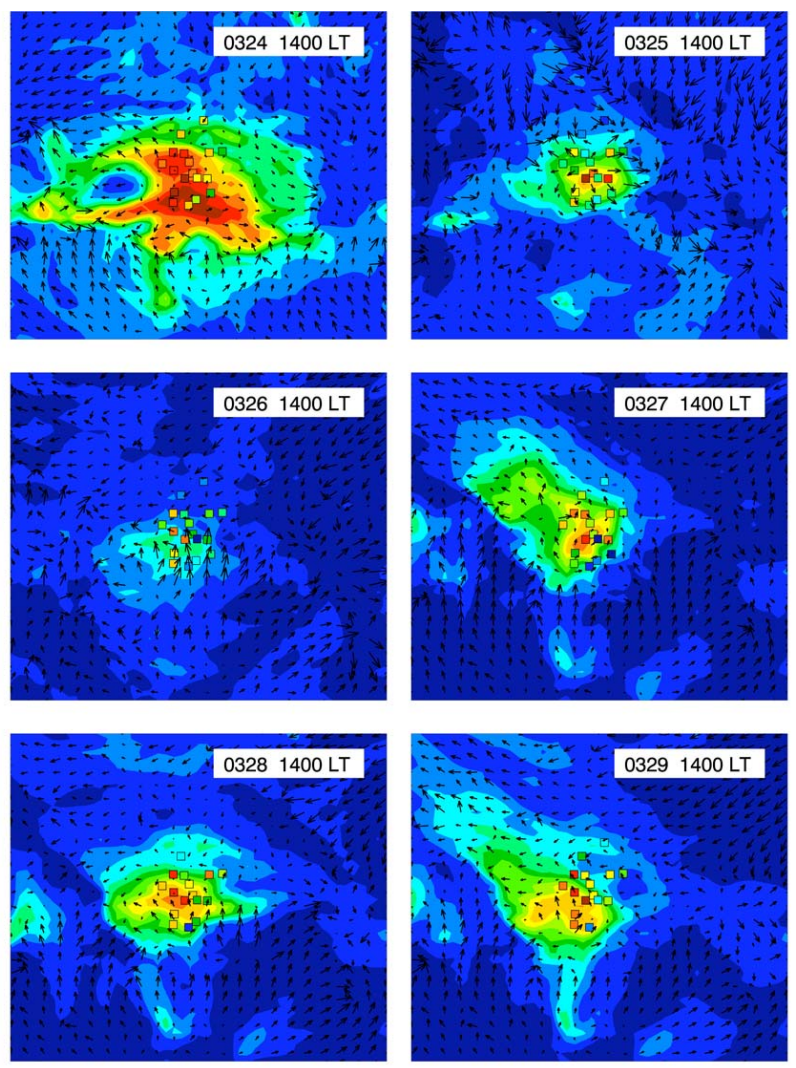

$4 \overrightarrow{\mathrm{ms}^{-1}}$

$\begin{array}{llllllllllllllll}0.0 & 0.1 & 0.2 & 0.3 & 0.4 & 0.5 & 0.6 & 0.7 & 0.8 & 0.9 & 1.0 & 1.2 & 1.5 & 2.0 & 3.0 & 5.0\end{array}$

(c)

CO Concentration (ppm)

Fig. 2. Continued.

period with convections, it may still play a role because the trash burning is less influenced by the convective precipitation.

The comparisons of modeled and PMF results (called "observed" from now on even if they are really the results of an observation-based model) for diurnal profiles of POA and SOA concentrations at $\mathrm{T} 0$ and $\mathrm{T} 1$ are presented from Fig. 4c to g. The T2-SOA model simulates the POA diurnal variations reasonably well at $\mathrm{T} 0$ and $\mathrm{T} 1$ when the POA is nonvolatile (Fig. 4a and c). However, the T2-SOA model significantly underestimates the observed POA during rush hours from 27 and 29 March at T1 and on 28th and 29th at T0. During the period from 24 to 26 March, the T2-SOA model overestimates the observed POA during rush hours. In this time period, the early morning winds from the north of the basin transport the pollutants from the Tula industrial complex and cause the overestimation of POA at T1. 25 and 26 March are Saturday and Sunday, which also explain some of the different patterns of emissions. In addition, the T2-SOA model frequently overestimates the measured daytime POA at T0 and T1. The IOA of POA is 0.81 and 0.59 at T0 and T1
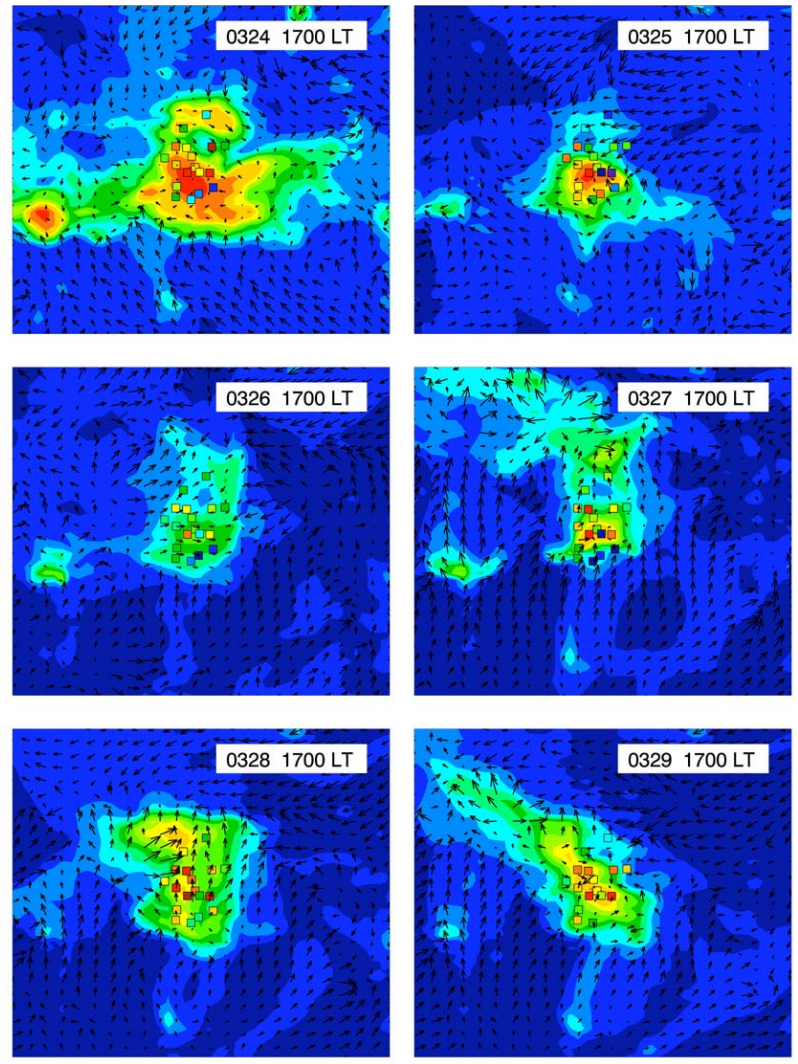

$4 \overrightarrow{\mathrm{ms}}^{-1}$

(c)

(d)

CO Concentration (ppm)
(Table 1), respectively, reasonably reflecting the performance of the T2-SOA model in simulating the POA variations at the two sites.

Hodzic et al. (2009) have used an air quality model to explore the processes controlling organic aerosols in the vicinity of Mexico City. Their model has reasonably reproduced the observed concentrations of POA at T0 and T1 with the non-volatile POA assumption. Their model results on POA are also in a good agreement with the study by Fast et al. (2009), who have also modeled during MILAGO and considered POA as non-volatile. It is worthy to note that Hodzic et al. (2009) and Fast et al. (2009) have used the same 2002 MCMA emissions inventory as adjusted by Lei et al. (2007). Although an updated 2006 MCMA inventory has been utilized in this study, our POA simulations in the T2-SOA model are comparable to those reported by Hodzic et al. (2009) and Fast et al. (2009) when the POA is considered as non-volatile.

When POA is assumed to be semi-volatile (Robinson et al., 2007) and adjusted and redistributed as Tsimpidi et al. (2010) in the NT-SOA model, the simulation of POA is 
Table 1. Statistical comparison of simulated and measured $\mathrm{OA}$ concentrations at $\mathrm{T} 0$ and $\mathrm{T} 1$ and $\mathrm{O}_{3}$ and $\mathrm{CO}$ concentrations at RAMA monitoring sites during the period 24 to 29 March 2006.

\begin{tabular}{|c|c|c|c|c|c|c|c|c|c|c|}
\hline \multirow[b]{2}{*}{ Case } & \multicolumn{5}{|c|}{ Urban Site (T0) } & \multicolumn{5}{|c|}{ Suburban Site (T1) } \\
\hline & $\mathrm{T} 2$ & NT & NT2 & NTE & NT2E & $\mathrm{T} 2$ & NT & NT2 & NTE & NT2E \\
\hline \multicolumn{11}{|l|}{ TOA } \\
\hline $\operatorname{NMB}(\%)$ & -31 & -10 & -5.7 & -6.1 & -2.6 & -47 & -50 & -43 & -48 & -42 \\
\hline $\operatorname{RMSE}\left(\mu \mathrm{g} \mathrm{m}^{-3}\right)$ & 7.7 & 5.6 & 4.9 & 5.2 & 4.8 & 4.4 & 4.3 & 4.1 & 4.2 & 4.0 \\
\hline IOA & 0.62 & 0.82 & 0.86 & 0.85 & 0.88 & 0.46 & 0.54 & 0.55 & 0.54 & 0.56 \\
\hline \multicolumn{11}{|l|}{ POA } \\
\hline $\operatorname{NMB}(\%)$ & 13 & 33 & 21 & 33 & 21 & 45 & -14 & -20 & -14 & -20 \\
\hline $\operatorname{RMSE}\left(\mu \mathrm{g} \mathrm{m}^{-3}\right)$ & 3.5 & 3.8 & 3.5 & 3.8 & 3.5 & 0.86 & 0.76 & 0.79 & 0.76 & 0.79 \\
\hline IOA & 0.81 & 0.85 & 0.86 & 0.85 & 0.86 & 0.59 & 0.56 & 0.52 & 0.56 & 0.51 \\
\hline \multicolumn{11}{|l|}{ SOA } \\
\hline NMB (\%) & -57 & -33 & -17 & -26 & -12 & -51 & -44 & -34 & -41 & -32 \\
\hline $\operatorname{RMSE}\left(\mu \mathrm{g} \mathrm{m}^{-3}\right)$ & 7.0 & 5.0 & 4.0 & 4.4 & 3.7 & 3.0 & 2.5 & 2.2 & 2.4 & 2.2 \\
\hline IOA & 0.49 & 0.70 & 0.83 & 0.78 & 0.86 & 0.43 & 0.58 & 0.65 & 0.60 & 0.67 \\
\hline \multicolumn{11}{|c|}{$\mathrm{RAMA} \mathrm{O}_{3}$ (NT case) } \\
\hline NMB (\%) 20 & & $\mathrm{RN}$ & $\mathrm{SE}(\mathrm{ppb})$ & 11 & & & & IOA & .95 & \\
\hline \multicolumn{11}{|c|}{ RAMA CO (NT case) } \\
\hline NMB (\%) 10 & & $\mathrm{RM}$ & $\mathrm{E}(\mathrm{ppm})$ & 0.50 & & & & IOA & .84 & \\
\hline
\end{tabular}
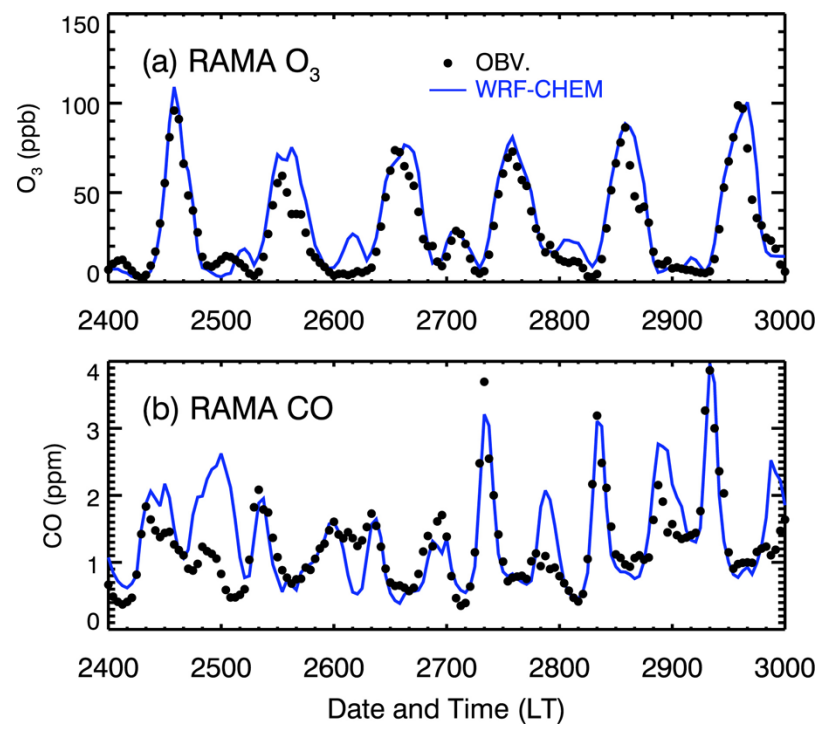

Fig. 3. Comparison of measured (black dots) and simulated (blue line) diurnal profiles of near surface hourly (a) $\mathrm{O}_{3}$ and (b) $\mathrm{CO}$ concentrations averaged over all monitoring sites. improved compared with the results from the T2-SOA model during almost the entire period against the measurement at T0, with the IOA increasing from 0.81 to 0.85 . The POA level in the NT-SOA model is higher during rush hours and slightly lower in the noontime and afternoon, compared to the results from the T2-SOA model, and is more consistent with the observations. As T0 is located near the urban center of Mexico City, it is directly influenced by the urban emissions. The POA is assumed to be semi-volatile in the NTSOA model, thus a large part of the emitted POA evaporates to form the POG and is oxidized to form SOA. In the early morning, large emissions of POA and low PBL height facilitate the condensation of the POGs due to evaporation of POA and result in high levels of the POA. In addition, the low $\mathrm{OH}$ concentrations are not favorable for the efficient oxidation of the POG due to evaporation of POA. On the contrary, in the noontime and afternoon, because the increase of the PBL height efficiently dilute the POA and POG, together with the high levels of $\mathrm{OH}$ radicals converting the POG rapidly into the OPOG to form SOA, more POA evaporates and the POA concentrations in the NT-SOA model are lower compared with that in the T2-SOA model. At T1, the NT-SOA model yields similar diurnal variation as the T2SOA model, but predicts less POA during the whole episode. The NMB of POA is $45 \%$ at T1 in the T2-SOA model, but $-14 \%$ in the NT-SOA model (Table 1). T1 is located in the 

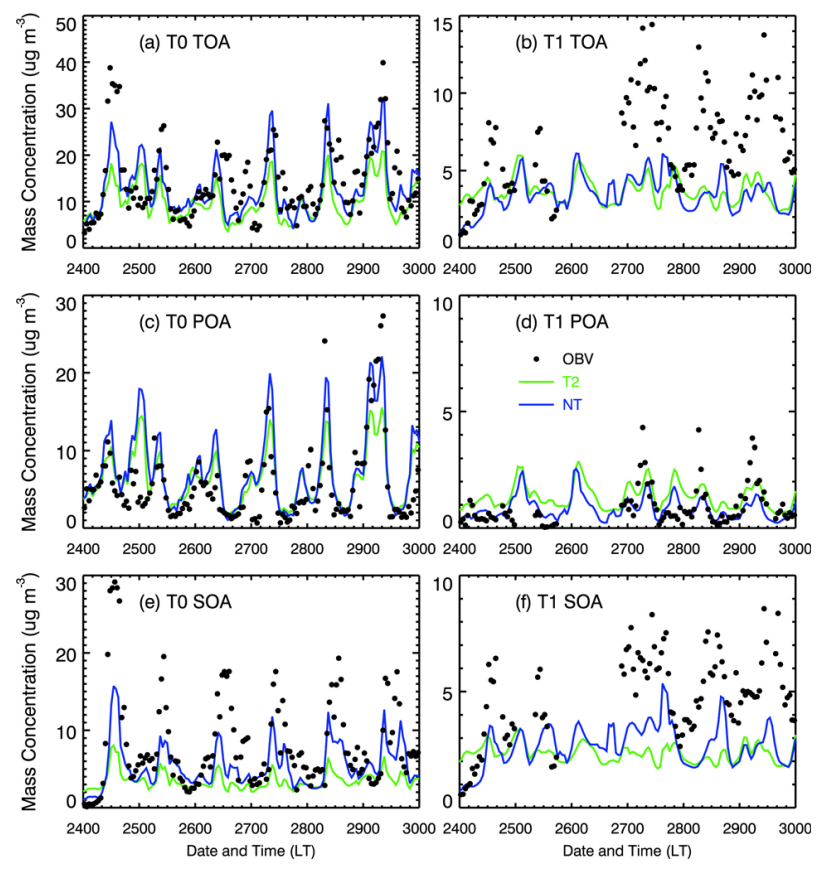

Fig. 4. Diurnal profiles of measured and simulated organic aerosol concentrations at T0 and T1 during the period from 24 to 29 March 2006. (a) TOA at T0, (b) TOA at T1, (c) POA at T0, (d) POA at $\mathrm{T} 1$, (e) SOA at T0, and (f) SOA at T1. Black dots: measurements; green line: the T2-SOA model; blue line: the NT-SOA model.

northwestern part of the Mexico City basin; it is used as a suburban background site (Molina et al., 2010). With the significant decrease of the OA emissions at $\mathrm{T} 1$ compared to T0, the NT-SOA model predicts less POA than the T2-SOA model because the emitted POA is apt to evaporate to keep the gas-particle partitioning.

In general, the T2-SOA model qualitatively reproduces the variability of SOA during daytime at T0 (Fig. 4b and d). For example, the observed SOA often exhibits two peaks around 10:00 and 14:00 LT, such as on 27 and 29 March. The T2SOA model replicates well the two peaks generally, although the timing of the second peak is sometimes delayed due to the slow movement of the simulated plumes in the afternoon. However, the T2-SOA model substantially underestimates the SOA concentrations compared to the observations and can only explain $25 \%$ of the observed SOA concentrations on average. In the T2-SOA model, the anthropogenic SOA precursors (mainly aromatics) contribute about $14 \%$ of the observed SOA concentrations during the simulation period, comparable to the results of Dzepina et al. (2009). Although Dzepina et al. (2009) have employed the updated aromatic $\mathrm{SOA}$ yields from recent chamber experiments ( $\mathrm{Ng}$ et al., 2007) in a photochemical box model constrained using observed SOA precursors, the traditional SOA model still fails to yield sufficient SOA concentrations to match the observations by a factor of 7. Hodzic et al. (2009) also reported that less than $15 \%$ of the observed SOA within Mexico City can be explained by the traditional mechanism based on oxidation of anthropogenic precursors.

On the other hand, the NT-SOA model significantly improves the SOA simulations at T0 compared to those from the T2-SOA model with about $100 \%$ enhancement of the SOA production, but the predicted SOA is still lower during daytime by a factor of about 2 compared to the PMF results. The SOA production from anthropogenic precursors is increased by $33 \%$ in the NT-SOA model compared to the T2SOA model, and contributes $36 \%$ of the predicted SOA concentrations during the six-day simulation period. The SOA production from the oxidation of anthropogenic VOCs is increased by $33 \%$ in the NT-SOA model compared to the T2SOA model, and contributes $36 \%$ of the predicted SOA concentrations during the six-day simulation period. Compared to the T2-SOA model, the higher SOA mass yield from anthropogenic aromatics in the NT-SOA model is the main reason for additional SOA formation. In Fig. SI-1, the SOA mass yield from toluene used in the NT-SOA model is about 4 times higher than that in the T2-SOA model when the total mass concentration of $\mathrm{OA}$ is $10 \mu \mathrm{g} \mathrm{m}^{-3}$. In addition, in terms of gas-phase partitioning, the NT-SOA model produces more OA than the T2-SOA model, therefore even if the yield curves were the same, the amount of SVOC in the condensed phase would be higher in the NT-SOA model. The most important source of the predicted SOA concentrations is the aging of the semi-volatile POA, with about $45 \%$ contribution. The biogenic precursors also provide $19 \%$ of the predicted SOA concentrations. On average, the NT-SOA model produces about $50 \%$ of the observed SOA at T0 during the simulation period. In the case study of Dzepina et al. (2009) in Mexico City, if the mechanism in Robinson et al. (2007) is included, they can close the gap in SOA mass between measurements and models with large contribution of SOA from glyoxal. However, in the present study, although the NTSOA model has included the SOA contributions from semivolatile POA and high yield of SOA formation from anthropogenic aromatics, there still exist considerably large discrepancies between measurements and models during daytime, particularly in the morning. On average, the T2-SOA and NT-SOA model both underestimate the observed SOA at T0, with the NMB of $-57 \%$ and $-33 \%$, respectively, although the NT-SOA model performs much better than the T2-SOA model, with the IOA increased from 0.49 to 0.70 and the RMSE decreased from 7.0 to $5.0 \mu \mathrm{g} \mathrm{m}^{-3}$.

At T1, the observed SOA exhibits distinctly two peaks in the morning and afternoon. The T2-SOA model severely underestimates the observed SOA concentrations during daytime and can only explain $21 \%$ of the observation. The NTSOA model fails to produce the first peak in the morning and also underestimates the second peak in the afternoon, which is due to the outflow from the polluted urban area that the model fails to predict accurately. The NT-SOA model predicts $32 \%$ of the observed SOA mass at $\mathrm{T} 1$, about $50 \%$ 
more than that from the T2-SOA model. About $15 \%$ of the predicted SOA concentrations are contributed by the anthropogenic precursors during the six-day period. The biogenic precursors provide $30 \%$ of the predicted SOA concentrations, more than that from the anthropogenic precursors, demonstrating the significant contribution of SOA from biogenic sources at the suburban background site $\mathrm{T} 1$. The aging of the semi-volatile POA contributes about $55 \%$ of the predicted SOA concentrations.

In the modeling study of Hodzic et al. (2010) for Mexico City, the condensable oxidation products from both anthropogenic and biogenic precursors were lumped into 9 groups of surrogate compounds, and the mechanisms suggested by Robinson et al. (2007) and Grieshop et al. (2009) were used to simulate the SOA formation from POG and IVOC. Hodzic et al. (2010) found that the predicted production from anthropogenic and biomass burning POG and IVOC represents $40-60 \%$ of the total measured SOA at the surface in the onemonth simulation from 1 to 31 March 2006 in and around Mexico City. In the present study, the predicted SOA from POG and IVOC by the mechanism of Robinson et al. (2007) represents about $22 \%$ of the observation in the urban area of Mexico City, less than those in Hodzic et al. (2010). In a similar study on an episode in April 2003, Tsimpidi et al. (2010) using the volatility basis set framework estimated that the non-traditional SVOCs (or POGs) and IVOC precursors contribute $10-20 \%$ to the OA inside Mexico City.

Figure 5 shows the diurnal cycles of observed and simulated TOA, POA, and SOA concentrations at T0 and T1 averaged over the simulation period. The T2-SOA and NTSOA models both underestimates the observed TOA at T1, producing about only half of the observed values. At T0, the T2-SOA model underestimates the observed TOA during daytime, and although the NT-SOA model improves the TOA simulations, the underestimation of TOA is still large between 10:00 and 16:00 LT. At T1, the T2-SOA model substantially underestimates the observed POA concentrations during rush hours but overestimates in the rest of the day. The NT- SOA models predict less POA mass compared to the T2SOA model during rush hours but successfully produce the observations in the remaining time. In addition, the T2-SOA model fails to yield the high level of the observed SOA mass during daytime. The NT-SOA model improves the SOA simulations in the afternoon, but still underestimates the observation, which is possibly caused by missing background SOA transport and will be investigated in more detail in a subsequent section. At T0, the T2-SOA and NT-SOA models show good performance in simulating the POA diurnal cycles, but the modeled POA concentrations in the NT-SOA model are more consistent with the observations than those from the T2-SOA model during rush hours and daytime. The NT-SOA model still substantially underestimates the observed SOA concentrations between 08:00 and 16:00 LT, which is plausibly attributed to the conditions used in simulations, such as meteorological fields, boundary conditions, emissions, $\mathrm{OH}$
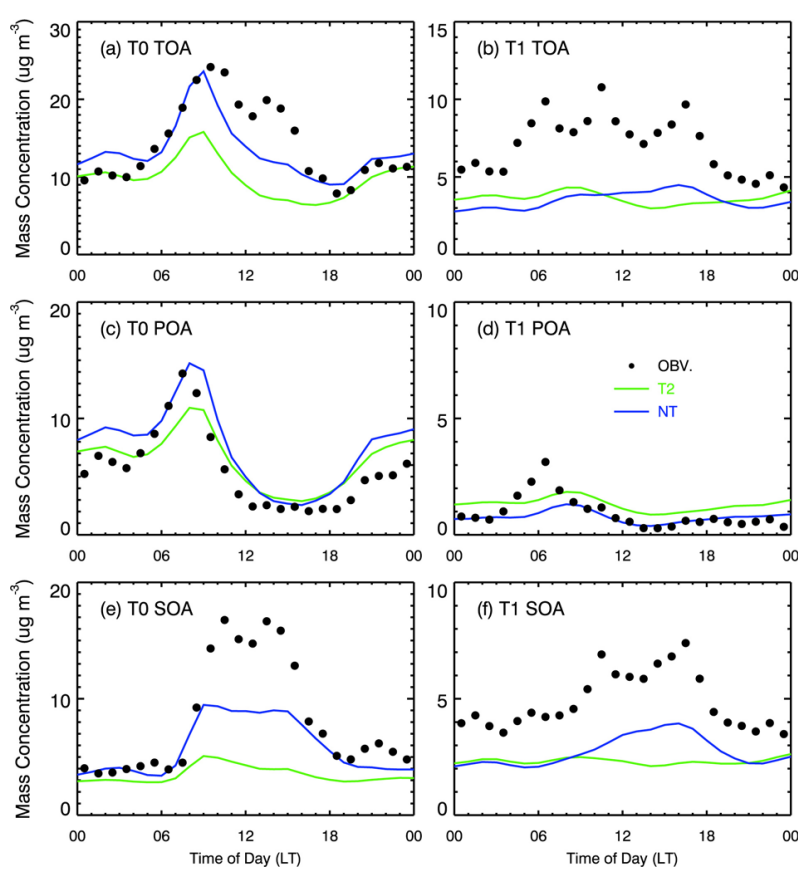

Fig. 5. Diurnal cycles of measured and simulated organic aerosol concentrations at $\mathrm{T} 0$ and $\mathrm{T} 1$ averaged during the period from 24 to 29 March 2006. (a) TOA at T0, (b) TOA at T1, (c) POA at T0, (d) POA at T1, (e) SOA at T0, and (f) SOA at T1. Black dots: measurements; green line: the T2-SOA model; blue line: the NTSOA model.

treatment, aging of SVOC and IVOC, etc. One of the most important factors dominating the performance of air quality models is the simulation of meteorological fields. However, according to the $\mathrm{O}_{3}$ and $\mathrm{CO}$ simulations (Figs. 2 and 3), the WRF-CHEM model generally performs well in simulating the plume evolution and movement during daytime, indicating the reasonable simulation of meteorological fields. In the following sections, we will discuss the major uncertainties in the OA simulations not including meteorological fields.

\subsection{Uncertainties in SOA simulations}

\subsubsection{Emissions inventory}

The uncertainties in emissions inventory directly influence the simulation of the SOA precursors and the formation of SOA in air quality models. In the SAPRC99 chemical mechanism used in the study, the major anthropogenic SOA precursors are aromatics, lumped into ARO1 and ARO2. ARO1 mainly includes toluene, benzene, ethylbenzene, and other aromatics with the reaction rate with $\mathrm{OH}(\mathrm{kOH})$ less than $2 \times 10^{4} \mathrm{ppm}^{-1} \mathrm{~min}^{-1}$. ARO2 includes xylene, trimethylbenzene, and other aromatics with $\mathrm{kOH}$ greater than $2 \times 10^{4} \mathrm{ppm}^{-1} \mathrm{~min}^{-1}$. Figure 6a shows the comparison of simulated ARO1 with the total of observed toluene, benzene, and ethylbenzene at T0. The WRF-CHEM model generally 
follows the variation of the total of observed toluene, benzene, and ethylbenzene from 24 to 26 March, but overestimates during daytime. During the period from 27-29 March, the model performs reasonably well in simulating the observations but underestimates during rush hours on 28th and 29th. The averaged simulated ARO1 at T0 during the sixday episode is $12.6 \mathrm{ppb}$, close to the observed $12.2 \mathrm{ppb}$. In Fig. 6b, the simulated ARO2 is compared with the total of observed m-xylene, o-xylene, p-xylene, naphthalene, and 135trimethylbenzene. In general, the WRF-CHEM model successfully reproduces the variability of the observation during daytime but often underestimates. The averaged simulated $\mathrm{ARO} 2$ is about $10.4 \mathrm{ppb}$, less than the observed $14.5 \mathrm{ppb}$, which is consistent with the results in Song et al. (2010).

Monoterpenes and isoprene are the main biogenic precursors considered in the SAPRC99 chemical mechanism. Figure 7 presents the comparison of modeled and PTR-MS observed monoterpene and isoprene at $\mathrm{T} 0$ during the period of 24-29 March. The observed peak isoprene concentrations occur during traffic rush hours, showing a strong anthropogenic signature (Hodzic et al., 2009). Therefore, when an anthropogenic source of isoprene as suggested by Borbon et al. (2001) is included, the model successfully reproduces the isoprene peak in the morning (Fig. 7a). However, the model frequently overestimates the observation in the evening, which is attributed to the transport of isoprene from the mountains surrounding Mexico City. The model substantially underestimates monoterpene concentrations during daytime and also fails to simulate the observed peak time in the early morning (Fig. 7b). However, considering the observed low level of monoterpene during daytime, the underestimation of monoterpene might not contribute significantly to the SOA evaluation.

The simulated POA concentrations in the T2-SOA and NT-SOA models are comparable to the measurement at T0, indicating that the POA emissions used in this study are generally reasonable in the urban area. Hence, from the point of view of the EI, the underestimation of $\mathrm{ARO} 2$ contributes to one of the important uncertainties in the evaluation of SOA formation.

The distribution of POA emissions in the NT-SOA model might also constitute a critical uncertainty for the SOA simulations. Tsimpidi et al. (2010) have examined the sensitivity of SOA simulations to the volatility distribution of the POA emissions. The volatility distribution of the POA emissions in the base case of Tsimpidi et al. (2010) was the same as the present study (Table SI-5). In their low volatility case, where the emissions in the low volatility bins $\left(C^{*}: 10^{-2}-10^{2}\right.$ $\mu \mathrm{g} \mathrm{m}^{-3}$ ) were doubled and the emissions in the high volatility bins were set to zero, they found that the predicted SOA is increased by $0.5 \mu \mathrm{g} \mathrm{m}^{-3}$ compared with the base case. The doubled emissions of the IVOCs in the high volatility bins $\left(C^{*}: 10^{4}-10^{6} \mu \mathrm{g} \mathrm{m}^{-3}\right)$ also result in $0.5 \mu \mathrm{g} \mathrm{m}^{-3} \mathrm{SOA}$ more than that in the base case.
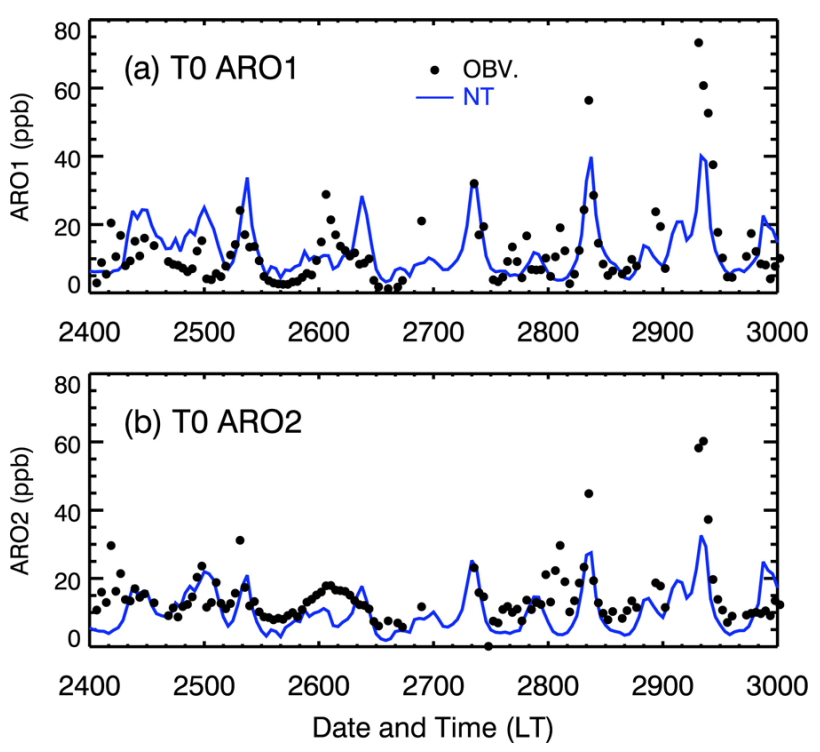

Fig. 6. Comparison of simulated (a) ARO1 and (b) ARO2 with measurements at T0 during the period from 24 to 29 March 2006. Black dots: measurements; blue line: the NT-SOA model simulations.
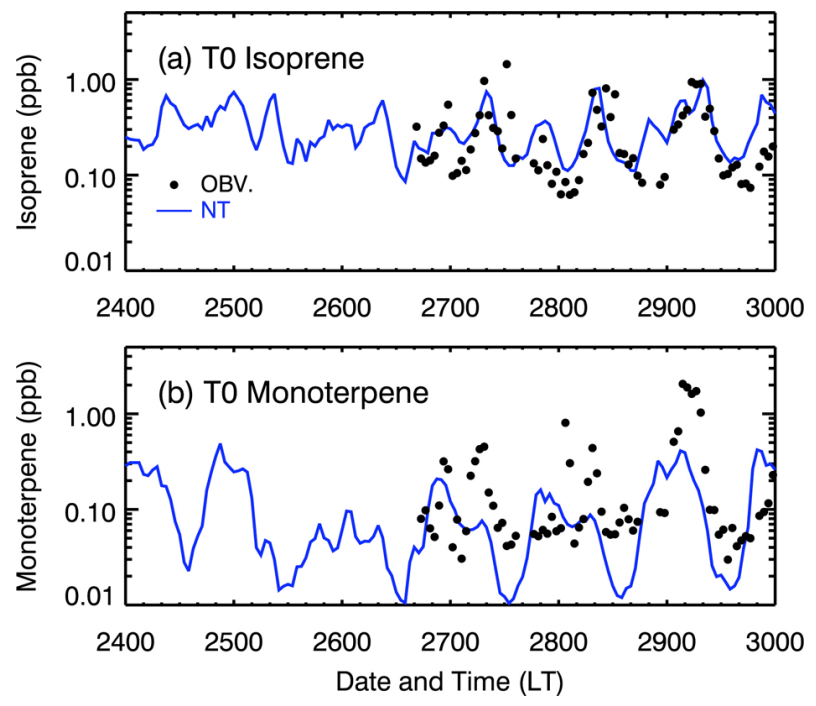

Fig. 7. Same as Fig. 6, except for (a) isoprene and (b) monoterpene.

\subsubsection{SOA contributions from dicarbonyl compounds}

Recent chamber experiments have indicated that dicarbonyl compounds, such as glyoxal and methylglyoxal, may play a role in the SOA formation via aerosol uptake and cloud processing (e.g., Carlton et al., 2006, 2007; Zhao et al., 2006). Volkamer et al. (2007) and Dzepina et al. (2009) have suggested that the contribution of glyoxal can explain at least $15 \%$ of the SOA formation in Mexico City. Fu et al. (2009) have found that inclusion of dicarbonyl SOA doubles the 
SOA contribution to water soluble organic carbon aerosol at all altitudes over eastern North America. Considerable uncertainty remains regarding the irreversible uptake coefficient of glyoxal on aerosol surfaces, varying from $4 \times 10^{-4}$ to $7.3 \times 10^{-3}$ (Liggio et al., 2005; Volkamer et al., 2007; de Hann et al., 2009). Although the irreversible uptake for methylglyoxal is still controversial, recent studies have supported its potential role in SOA formation (Zhao et al., 2006; Sareen et al., 2010). In this study, the SOA formation from glyoxal and methylglyoxal is parameterized as a first-order irreversible uptake by aerosol particles, with a reactive uptake coefficient of $3.7 \times 10^{-3}$ for glyoxal and methylglyoxal (Liggio et al., 2005; Zhao et al., 2006; Volkamer et al., 2007).

Figure $8 \mathrm{a}$ and $\mathrm{b}$ show the temporal variation of SOA concentrations from glyoxal and methylglyoxal at T0 and T1. At T0, glyoxal has its largest contribution to the SOA formation on $24 \mathrm{March}$, about $1.2 \mu \mathrm{g} \mathrm{m}^{-3}$. The contribution from methylglyoxal is more than that from glyoxal. On average, the irreversible uptake of glyoxal can explain about $2.7 \%$ of the observed SOA mass at T0 and the contribution from methylglyoxal can be up to 3.3\%. Dzepina et al. (2009) have used a photochemical box model to evaluate the contribution of several recently proposed SOA mechanisms to the SOA formation in a case study during MCMA-2003. They have found that the amount of SOA from glyoxal explains about $17 \%$ of observed SOA mass. The case investigated by Dzepina et al. (2009) is similar to that occurring on 24 March in this study in terms of meteorology and the SOA development. However, in the simulation with the NT-SOA model, glyoxal only contributes $3.5 \%$ to the observed SOA during the time period from 00:60 to 14:00 LT, only about $20 \%$ of the estimation by Dzepina et al. (2009). It is worthy to note that the WRF-CHEM model underestimates the glyoxal concentrations compared to the measurement at $\mathrm{T} 0$ by a factor of 2 (Fig. 8c), which can partially explain the lower SOA production. Additionally, in the study of Dzepina et al. (2009), the modeled gas-phase glyoxal was 2-6 times higher than the direct DOAS measurements, which caused much more SOA formation from glyoxal when Henry's law is used to partition gas-phase glyoxal into aerosol liquid water with an effective constant $H_{\text {eff }}=4 \times 10^{9} \mathrm{M} \mathrm{atm}^{-1}$, constrained by the observed glyoxal. At T1, the contribution of glyoxal and methylglyoxal to the SOA formation is small, less than $2 \%$ of the observation (Fig. $8 \mathrm{~b}$ ).

\subsubsection{Uncertainties from SOA formation mechanisms}

The mechanism of Robinson et al. (2007) used in the NTSOA model has been updated by Grieshop et al. (2009) to better match the evolution of chamber SOA from wood smoke. In the updated mechanism, the $k_{\mathrm{OH}}$ is decreased to $2 \times 10^{-11} \mathrm{~cm}^{3}$ molec $^{-1} \mathrm{~s}^{-1}$ and every generation of oxidation decreases the saturation concentration of the products by two orders of magnitude and increases the mass by $40 \%$ per oxidation step. In addition, in the mechanism of Robin-
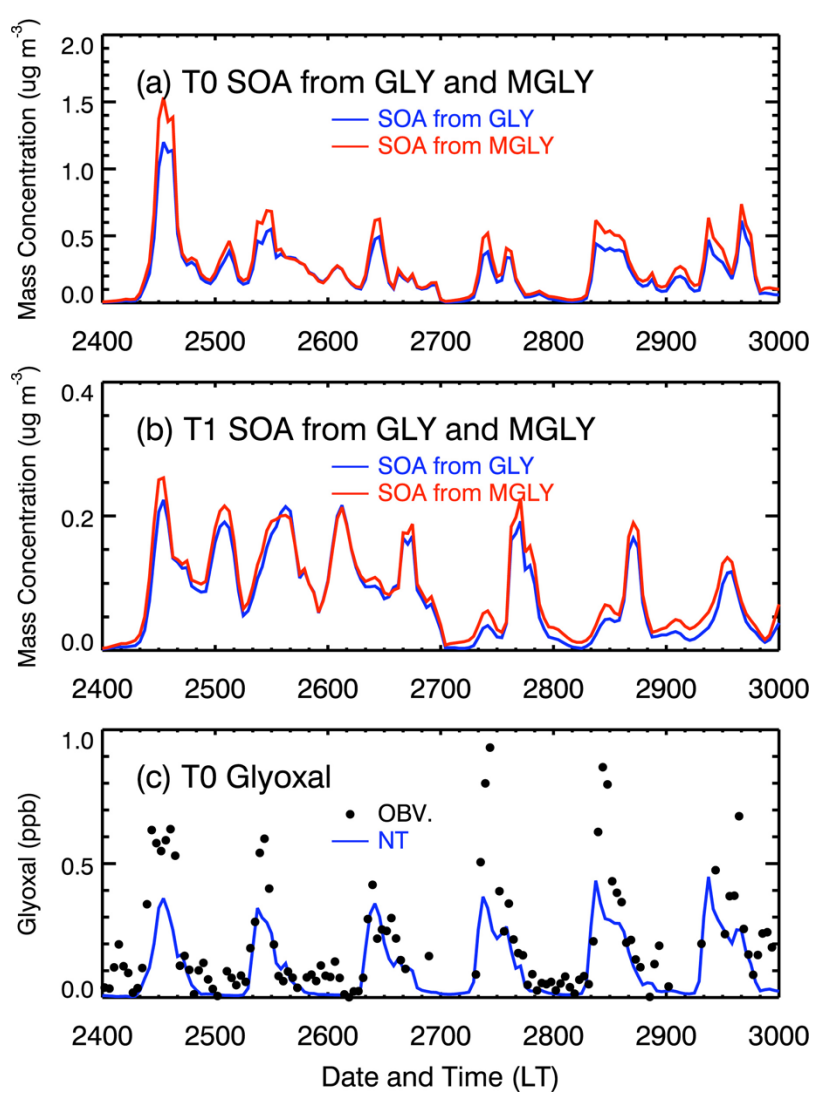

Fig. 8. Diurnal profiles of (a) SOA concentrations from glyoxal and methylglyoxal at T0, (b) at T1, and (c) glyoxal concentrations at T0. In (a) and (b), the red and blue lines represent the SOA contributions from glyoxal and methylglyoxal, respectively. In (c), black dots are measurements and blue line denotes the simulations in the NT-SOA model.

son et al. (2007), the enthalpy of vaporization for calculation of $C^{*}$ ranges from 112 to $64 \mathrm{~kJ} \mathrm{~mol}^{-1}$, but it is decreased to $77-46 \mathrm{~kJ} \mathrm{~mol}^{-1}$ in the mechanism of Grieshop et al. (2009).

The new mechanism is also incorporated into the NT-SOA model, which is referred to as the NT2-SOA model. A sensitivity study is conducted using the NT2-SOA model with the same initial and boundary conditions as the NT-SOA model. As shown in Fig. 9a and b, the NT2-SOA model improves the TOA simulations compared to the NT-SOA model at T0 and T1, but the underestimation at T1 is still large. The NT2SOA model generally produces less POA mass than the NTSOA model at T0 and T1, especially during nighttime and rush hours, which is caused by the decrease of the enthalpy of vaporization of POG in the NT2-SOA model. When the temperature is the same, the lower enthalpy of vaporization of POG results in higher effective saturation concentration of POG and is not favorable for the condensation of POG to form POA in the NT2-SOA model, compared to the NT-SOA model. The NT2-SOA model slightly improves the POA simulation at T0 compared to the NT-SOA model (Fig. 9c), 
with the RMSE decreased from 3.8 to $3.5 \mu \mathrm{g} \mathrm{m}^{-3}$ and IOA increased from 0.85 to 0.86 . The NT2-SOA model considerably improves the SOA production compared to the NT-SOA model at T0 (Fig. 9e), with the IOA increased from 0.70 to 0.83 and the RMSE decreased from 5.0 to $4.0 \mu \mathrm{g} \mathrm{m}^{-3}$. On average, the SOA mass in the NT2-SOA model is increased by $1.2 \mu \mathrm{g} \mathrm{m}^{-3}$ compared to the NT-SOA model, which is principally attributed to the aging of the semi-volatile POA (about $1.1 \mu \mathrm{g} \mathrm{m}^{-3}$ ). Although the oxidation rates of semivolatile species with $\mathrm{OH}$ are decreased by $50 \%$ in the NT2SOA model, several factors are favorable for the SOA production. Compared to the NT-SOA model, the decrease of the enthalpy in the NT2-SOA model withholds more POG in the gas phase for oxidation. The $C^{*}$ decrease of the products by two orders of magnitude per oxidation step also increases the partitioning efficiency to the particle phase. The $40 \%$ mass increase per oxidation step further enhances the SOA production in the NT2-SOA model. The NT2-SOA model produces $66 \%$ of the observed SOA mass at T0, but the NT2SOA model still underestimates during daytime. At T1, the NT2-SOA model improves the SOA simulations, but the underestimation is still significant in the morning (Fig. 9f). In the afternoon, the NT2-SOA model remarkably enhances the SOA concentrations, showing the impacts of slow aging of the semi-volatile POA accompanied with more mass addition, but the simulations are still lower than the observation. In terms of the RMSE and IOA at T1, the improvement of the SOA simulations in the NT2-SOA model is also significant compared to the NT-SOA model.

\subsubsection{Uncertainties from $\mathrm{OH}$ simulations}

The aging of primary organic components in the NT-SOA and NT2-SOA models is an efficient OH consumption process due to the fast reaction rate of these compounds with $\mathrm{OH}$. Therefore, the aging process in the NT-SOA and NT2SOA models inevitably decreases the $\mathrm{OH}$ concentration, which in turn inhibits the aging process. In order to evaluate the impacts of the aging process on the $\mathrm{OH}$ concentrations and further the SOA formation, we have further modified the NT-SOA and NT2-SOA models, assuming that the aging process does not have feedback on $\mathrm{OH}$ in the gas-phase chemistry. Hereafter, we refer to the NT-SOA and NT2-SOA models without $\mathrm{OH}$ feedback as the NTE-SOA and NT2ESOA models, respectively.

Figure 10 shows the diurnal cycle of $\mathrm{OH}$ concentrations in the NT-SOA and NTE-SOA model at T0 and T1. Compared with the measurements at $\mathrm{T} 0$, the $\mathrm{OH}$ concentrations are substantially underestimated during morning and noontime in the NT-SOA. When the aging process does not feedback on $\mathrm{OH}$ in the gas-phase chemistry in the NTE-SOA model, the simulated $\mathrm{OH}$ concentrations are enhanced slightly, more consistent with the measurement than that in the NT-SOA model. At $\mathrm{T} 1$, the model frequently overestimates the observed $\mathrm{OH}$ concentrations in the afternoon whether the $\mathrm{OH}$
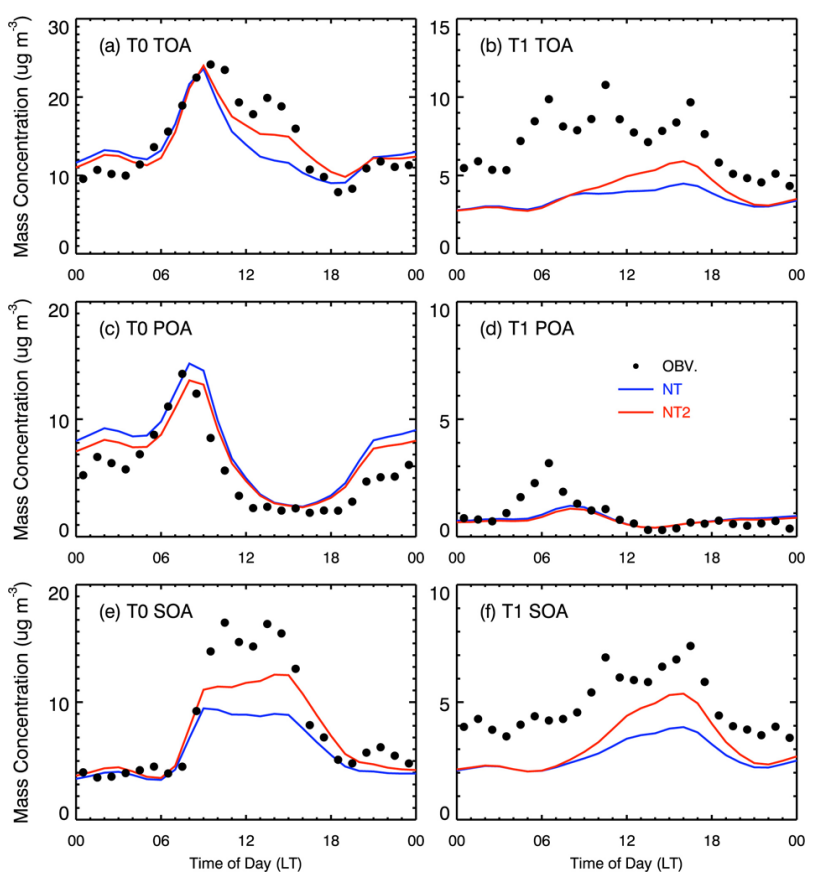

Fig. 9. Same as Fig. 5, except that the blue line represents the NTSOA model and the red line denotes the NT2-SOA model.

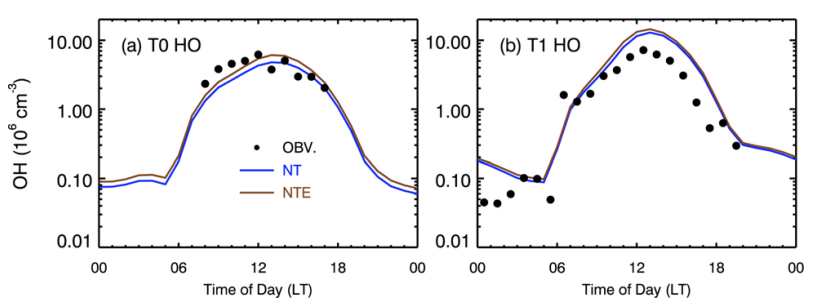

Fig. 10. $\mathrm{OH}$ diurnal cycles (a) at $\mathrm{T} 0$ and (b) at $\mathrm{T} 1$ averaged during the period from 24 to 29 March 2006. Black dots: measurements; blue line: the NT-SOA model; brown line: the NTE-SOA model (without $\mathrm{OH}$ feedback).

feedback during the aging process were included or not. The overestimation of the $\mathrm{OH}$ concentrations at $\mathrm{T} 1 \mathrm{might}$ be explained by the unsuccessful simulations of cumulus clouds that are not resolved reasonably, or the dust aerosols which frequently influence the $\mathrm{T} 1$ site and are not considered in the present WRF-CHEM model.

The NT2E-SOA model reproduces the observed TOA concentrations generally well at T0, with an IOA of 0.88 . Although the NT2E-SOA model yields more TOA mass than the NTE-SOA model at T1, it still underestimates the observed TOA substantially. The SOA simulations are improved in the NTE-SOA and NT2E-SOA models at T0 compared with the results in the NT-SOA and NT2-SOA models, and SOA production is enhanced by around $18 \%$ and $10 \%$ during daytime, respectively (Fig. 11). The NT2E-SOA 

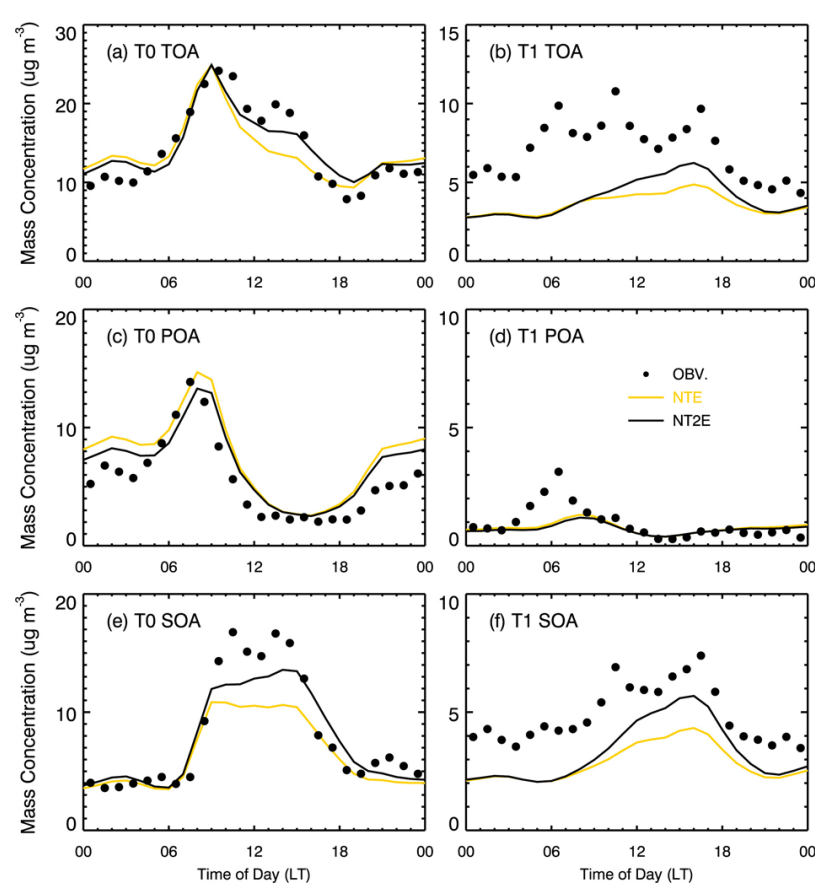

Fig. 11. Same as Fig. 5, except that the brown line represents the NTE-SOA model (without $\mathrm{OH}$ feedback) and the black line denotes the NT2E-SOA model (without OH feedback).

model performs better than the NTE-SOA model, and the IOA in the NT2E-SOA model is 0.86 , greater than 0.78 in the NTE-SOA model. The NT2E-SOA model yields $70 \%$ of the observed SOA at T0, greater than $56 \%$ obtained by the NTE-SOA model. However, even though the aging process does not have feedback on $\mathrm{OH}$ in the gas-phase chemistry in the NTE-SOA and NT2E-SOA models, the SOA concentrations are still underestimated between 08:00 and 16:00 LT. At $\mathrm{T} 1$, in the afternoon, the NT2E-SOA model reproduces much more SOA than the NTE-SOA model, indicating that the $\mathrm{OH}$ enhancement accelerates the aging process efficiently.

\subsubsection{Discussion}

The non-traditional SOA models still underestimate the observed SOA concentrations between 08:00 and 16:00 LT. Furthermore, among all the SOA models, the NT2E-SOA model yields the largest SOA mass, and the underestimation is about $3.0 \mu \mathrm{g} \mathrm{m}^{-3}$ or $21 \%$ on average between $8: 00$ and 16:00 LT, within the uncertainty of the AMS measurements and PMF analysis. Several sensitivity analyses have also been conducted to attempt to close the SOA gap between measurements and the WRF-CHEM model.
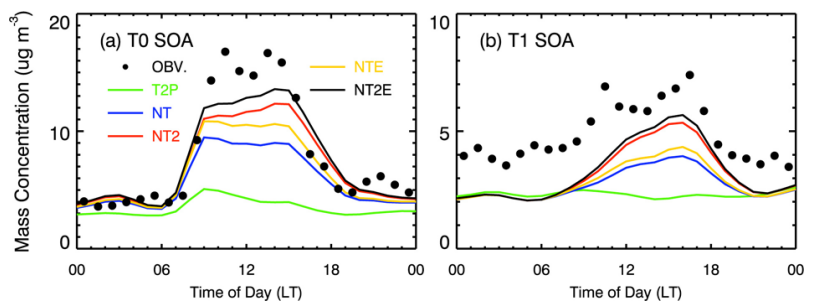

Fig. 12. Diurnal cycles of measured and simulated SOA concentrations at T0 and T1 averaged during the period from 24 to 29 March 2006. (a) SOA at T0 and (b) SOA at T1. Black dots: measurements; green line: the T2-SOA model; blue line: the NT-SOA model; red line: the NT2-SOA model; brown line: the NTE-SOA model; black line: the NT2E-SOA model. All the non-traditional SOA models include the SOA contributions from glyoxal and methylglyoxal.

\section{Impacts of dicarbonyl compounds}

Figure 12 shows the SOA comparison when the contribution of glyoxal and methylglyoxal to the SOA formation is included in the non-traditional models. At T1, the enhancement of SOA due to glyoxal and methylglyoxal is insignificant, contributing about $3.0 \%$ of the observation. The SOA simulations at T0 is improved with the inclusion of the contribution from glyoxal and methylglyoxal, and the gap between the NT2E-SOA model and measurements is reduced to $2.0 \mu \mathrm{g} \mathrm{m}^{-3}$ or $14 \%$ averaged between 08:00 and 16:00 LT.

\section{Impacts of aromatic emissions}

One of the possible reasons for the daytime gap between the model and the observations is the underestimation of ARO2 during daytime, which plays an important role in the SOA formation and also influences the $\mathrm{OH}$ level. In addition, the uncertainty of the SOA formation from glyoxal also likely contributes to the underestimation of SOA during daytime in this study. Therefore, a sensitivity study is devised using the NT2E-SOA model, in which glyoxal yield from ARO1 and $\mathrm{ARO} 2$ is doubled and $\mathrm{ARO} 2$ emissions are increased by $30 \%$. The modeled ARO2 and glyoxal are generally in good agreement with the observation at T0 (Fig. 13a and b). The SOA mass is increased by 0.26 and $0.16 \mu \mathrm{g} \mathrm{m}^{-3}$ averaged during the whole episode from the enhancement of ARO2 and glyoxal at T0, respectively (Fig. 13c). The underestimation is further reduced to $\sim 0.87 \mu \mathrm{g} \mathrm{m}^{-3}$ or $6 \%$ on average between 08:00 and 16:00 LT, and the simulated SOA concentrations are in good agreement with the observation at T0, with the IOA of up to 0.90 (Table 2). In addition, glyoxal and methylglyoxal contribute up to $9.6 \%$ to the observed SOA mass at T0 and $4 \%$ at $\mathrm{T} 1$ when glyoxal concentrations are comparable to the measurements. Therefore, glyoxal and methylglyoxal play a noticeable role in the SOA formation in the urban region. However, it should be noted that we assess the SOA formation from glyoxal by increasing the 
Table 2. Statistical comparison of measured SOA concentrations and simulations from sensitivity studies based on the NT2E-SOA model at T0 and T1 during the period from 24 to 29 March 2006.

\begin{tabular}{lrrrr|rrrr}
\hline & \multicolumn{3}{c|}{ Urban Site (T0) } & \multicolumn{5}{c}{ Suburban Site (T1) } \\
\cline { 2 - 8 } Case & $\mathrm{BA}^{1}$ & $\mathrm{AD}^{2}$ & $\mathrm{VA}^{3}$ & $\mathrm{HB}^{4}$ & $\mathrm{BA}^{1}$ & $\mathrm{AD}^{2}$ & $\mathrm{VA}^{3}$ & $\mathrm{HB}^{4}$ \\
\hline SOA & & & & & & & & \\
\hline NMB $(\%)$ & -12 & 1.3 & -3.0 & 8.9 & -32 & -27 & -24 & 3.3 \\
RMSE $\left(\mu \mathrm{g} \mathrm{m}^{-3}\right)$ & 3.7 & 3.4 & 3.6 & 3.8 & 2.2 & 2.1 & 2.1 & 1.6 \\
IOA & 0.86 & 0.90 & 0.88 & 0.88 & 0.67 & 0.68 & 0.69 & 0.77 \\
\hline
\end{tabular}

\footnotetext{
${ }^{1}$ Base case (the NT2E-SOA model); ${ }^{2}$ adjustment case with the doubled glyoxal yield from ARO1 and ARO2 and 30\% increase of ARO2 emissions in the NT2E SOA model. The SOA formation from glyoxal and methylglyoxal is included; ${ }^{3}$ the SOA from the oxidation of VOCs is aging with the reaction rate of $1 \times 10^{-11} \mathrm{~cm}^{3} \mathrm{molec}-1 \mathrm{~s}^{-1}$ with OH in the NT2E-SOA model; ${ }^{4}$ high background case with the background SOA of $3.5 \mu \mathrm{g} \mathrm{m}^{-3}$ in the NT2E-SOA model.
}

glyoxal concentrations comparable to measurements. When considering the uncertainty of the irreversible uptake coefficient of glyoxal on aerosol surfaces, ranging from $4 \times 10^{-4}$ to $7.3 \times 10^{-3}$ (Liggio et al., 2005), large uncertainties of the SOA formation from glyoxal still exist. For example, if the irreversible uptake coefficient of glyoxal on aerosol surfaces is set to be $4 \times 10^{-4}$, the simulated glyoxal agrees well with the observation at $\mathrm{T} 0$, but the SOA formation from glyoxal is reduced to $0.04 \mu \mathrm{g} \mathrm{m}^{-3}$, only $0.5 \%$ of the measurement on average.

\section{Contributions of aging of SVOCs from the oxidation of anthropogenic VOCs}

The chemical aging of the SVOCs produced from the oxidation of anthropogenic VOCs (hereafter referred to as ASVOCs) might also play an important role in the SOA formation, according to recent model results (Lane et al., 2008a; Stanier et al., 2008; Donahue et al., 2006; Tsimpidi et al., 2010). In order to evaluate the SOA contribution of the aging process of the A-SVOCs, a sensitivity study is performed based on the NT2E-SOA model, in which the A-SVOCs are assumed to follow the same chemical aging process as POG and IVOC in Robinson et al. (2007), but the rate constant with $\mathrm{OH}$ is reduced to $1 \times 10^{-11} \mathrm{~cm}^{3} \mathrm{molec}^{-1} \mathrm{~s}^{-1}$ as given by Murphy and Pandis (2009). Inclusion of the continued aging of A-SVOCs efficiently augments the SOA production, and the SOA mass from the anthropogenic VOCs is enhanced by $43 \%$ or $0.73 \mu \mathrm{g} \mathrm{m}^{-3}$ at $\mathrm{T} 0$ and $140 \%$ or $0.34 \mu \mathrm{g} \mathrm{m}^{-3}$ at T1 on average compared to the results without the aging of ASVOCs in the NT2E-SOA model. The aging of A-SVOCs improves the SOA simulations compared with the measurements (Fig. 14). At T0, the underestimation between 08:00 and 16:00 LT is reduced to $1.9 \mu \mathrm{g} \mathrm{m}^{-3}$ or $13 \%$ on average. At $\mathrm{T} 1$, the simulated SOA is in good agreement with the observations in the afternoon (Fig. 14b). However, the chemical aging of SOA from anthropogenic VOCs remains quite uncertain (George and Abbatt, 2010).
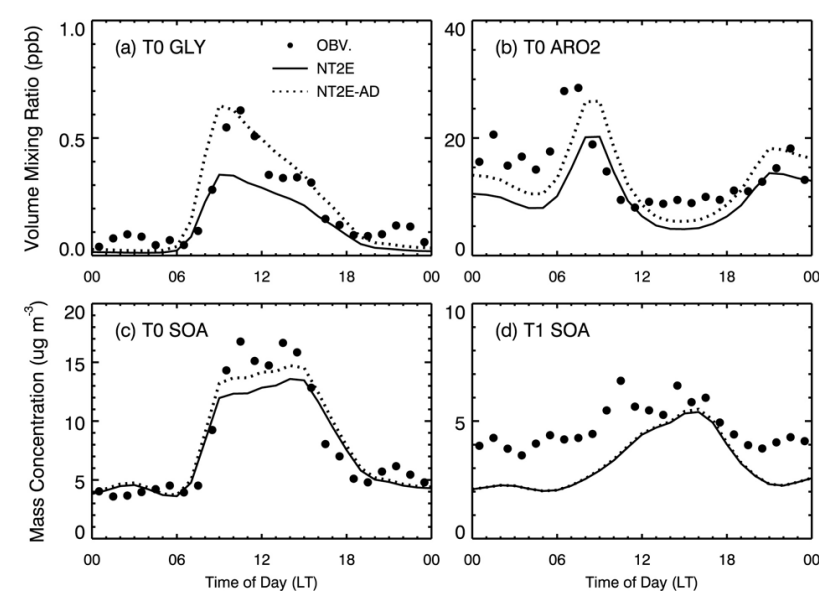

Fig. 13. Diurnal cycles of (a) glyoxal at T0, (b) ARO2 at T0, (c) SOA at T0, and (d) SOA at T1 averaged during the period from 24 to 29 March 2006. Black dots: measurements; black solid line: the NT2E-SOA model; black dotted line: NT2E-SOA model with high yield glyoxal from ARO1 and $\mathrm{ARO} 2$ and increased $\mathrm{ARO} 2$ emissions.

\section{Impacts of background transport SOA}

The transport of background SOA mass can also play an important role in the evaluation of the SOA simulations (Tsimpidi et al., 2010), therefore a sensitivity study with a high SOA boundary condition of $3.5 \mu \mathrm{g} \mathrm{m}^{-3}$ is performed in the NT2E-SOA model. The high boundary condition improve the SOA simulation between 08:00 and 16:00 LT at T0, but causes overestimation during nighttime (Fig. 15a). At T1, the high boundary condition increase the SOA concentrations before 12:00 LT to match the measurements, but results in marked overestimation in the afternoon (Fig. 15b). In order to further verify the importance of the transport of background SOA, we also compare the observed and simulated diurnal variation of the OA mass at T2, as shown in Fig. 15c. 


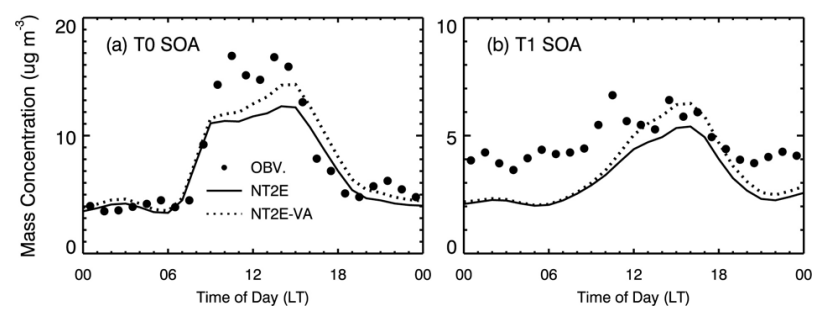

Fig. 14. Diurnal cycles of SOA (a) $\mathrm{T} 0$ and (b) at $\mathrm{T} 1$ averaged during the period from 24 to 29 March 2006. Black dots: measurements; black solid line: the NT2E-SOA model; black dotted line: NT2ESOA model with the aging of the organic condensable gases from the oxidation of anthropogenic precursors.

$\mathrm{T} 2$ is a regional background site located around $90 \mathrm{~km}$ to the north of Mexico City, isolated from major urban agglomerations and around $2 \mathrm{~km}$ from the closest road. High OA mass is observed at $\mathrm{T} 2$, ranging from 5 to $10 \mu \mathrm{g} \mathrm{m}^{-3}$ during daytime and from 4 to $7 \mu \mathrm{g} \mathrm{m}^{-3}$ during nighttime. The NT2E-SOA model significantly underestimates the observed OA mass at T2 when the low SOA boundary condition $\left(1.4 \mu \mathrm{g} \mathrm{m}^{-3}\right)$ is used in simulations. The underestimation of the OA mass at $\mathrm{T} 2$ is $51 \%$ or $3.3 \mu \mathrm{g} \mathrm{m}^{-3}$ during daytime and $34 \%$ or $1.6 \mu \mathrm{g} \mathrm{m}^{-3}$ during nighttime. However, when the high background condition of $3.5 \mu \mathrm{g} \mathrm{m}^{-3}$ is used in the NT2E-SOA model, the OA simulations is significantly improved at $\mathrm{T} 2$, with the daytime underestimation decreased to $23 \%$ or $1.6 \mu \mathrm{g} \mathrm{m}^{-3}$ and good agreement with observations during nighttime.

There are no POA emissions from biomass burning in the EI used in the simulations. Although we have attempted to reduce the impacts of biomass burning on the OA simulations by choosing an episode with less impacts from biomass burning (Aiken et al., 2009), the contribution to SOA from biomass burning is still not negligible, particularly in the suburban area. Therefore, the lack of POA emissions from biomass burning also likely contributes to the underestimation of SOA concentrations at T0 during daytime and in the morning at $\mathrm{T} 1$.

\section{Conclusions}

In the present study, a six-day episode from 24 to 29 March 2006 is simulated in Mexico City using the WRF-CHEM model with two different SOA approaches: (1) a traditional 2-product SOA model with non-volatile primary organic aerosols; (2) a non-traditional SOA model including the volatility basis-set modeling approach in which primary organic components are assumed to be semi-volatile and photochemically reactive and are distributed in logarithmically spaced volatility bins. OA simulations are compared with measurements at an urban site (T0) and a suburban site (T1) in Mexico City.
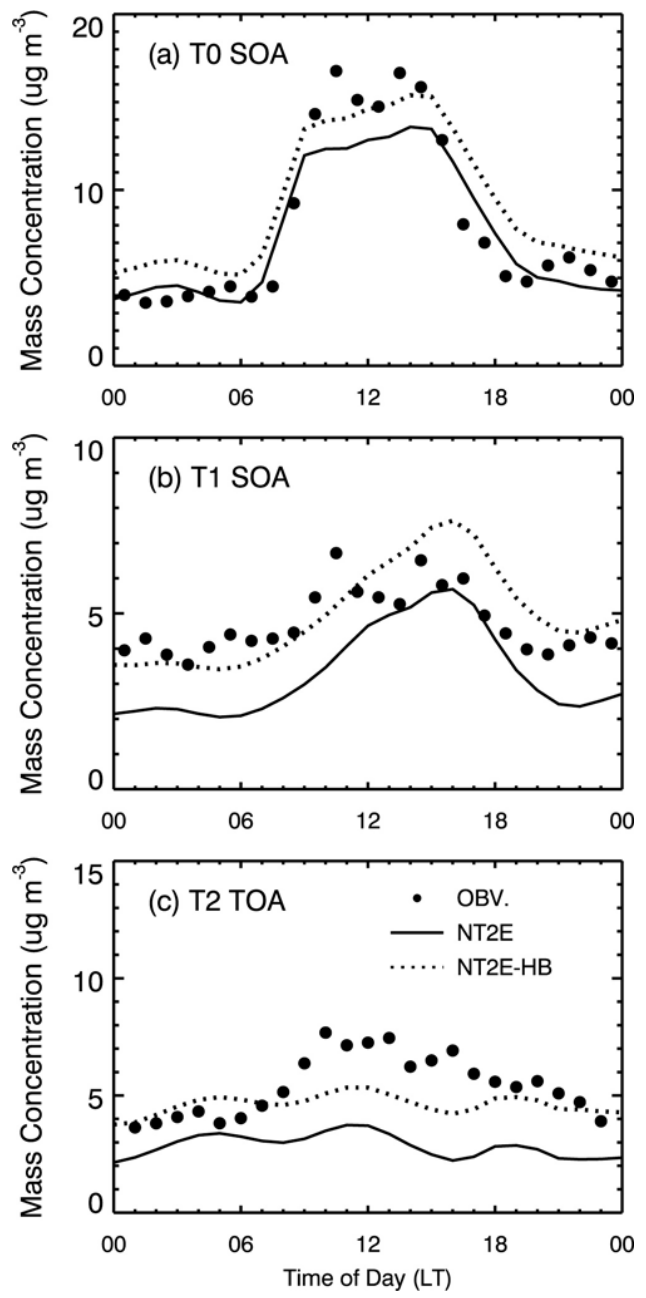

Fig. 15. Diurnal cycles of SOA (a) $\mathrm{T} 0$ and (b) at $\mathrm{T} 1$, and $\mathrm{OA}$ at T2 averaged during the period from 24 to 29 March 2006. Black dots: measurements; black solid line: the NT2E-SOA model; black dotted line: NT2E-SOA model with high background SOA.

The WRF-CHEM model generally performs well in modeling the daytime $\mathrm{O}_{3}$ and $\mathrm{CO}$, except the simulated plumes frequently move slowly in the afternoon. The simulated nighttime $\mathrm{O}_{3}$ and $\mathrm{CO}$ deviate significantly from the observation due to the difficulties in modeling the meteorological fields during nighttime. The NMB and RMSE of $\mathrm{O}_{3}$ are $20 \%$ and $11 \mathrm{ppb}$, respectively, and the IOA reaches $95 \%$. For CO, the NMB and RMSE are $10 \%$ and $0.5 \mathrm{ppm}$, respectively, and the IOA is $84 \%$.

The traditional SOA model generally significantly underestimates the TOA concentrations in the urban area during daytime and in the suburban area entirely. The IOAs in the urban and suburban area are 0.46 and 0.62 , respectively. The non-traditional SOA model improves the TOA simulations, particularly in the urban area with the IOA of over 0.82 , but still underestimates in the suburban area. The traditional 
SOA model performs reasonably well in simulating the POA concentrations in the urban area with the IOA of more than 0.81, but fails to reproduce the observed POA mass in the suburban area during rush hours. In addition, the traditional SOA model produces only around $14 \%$ of the observed SOA mass from the oxidation of anthropogenic aromatics, which is comparable to the other studies in Mexico City (Dzepina et al., 2009; Hozdic et al., 2009).

The non-traditional SOA model significantly improves the SOA simulation compared to the traditional SOA model, with more than $100 \%$ SOA enhancement, but still underestimates the observed SOA concentrations during daytime in the urban area whether using the mechanism of Robinson et al. (2009) or Grieshop et al. (2009). In the suburban area, the non-traditional SOA model still fails to reproduce the high level of observed SOA concentrations. The agreement of the simulated SOA with observations can be improved by changing the $\mathrm{OH}$ treatment, emissions, aging of SVOC and IVOC, and boundary conditions. Other factors, such as SOA formation pathways, or precursors which one simply has not accounted for, could cause the majority of the underestimation. Additionally, the non-traditional model also slightly improves POA simulations during daytime in the urban area and during the time period except rush hours in the suburban area compared to the traditional one.

In the non-traditional SOA model, the aging process of primary organic components considerably decreases the simulated $\mathrm{OH}$ levels, which in turn impacts the SOA formation. When the aging process does not have feedback on $\mathrm{OH}$ in the gas-phase chemistry in the non-traditional model, the SOA production in the non-traditional model is enhanced by more than $10 \%$ in the urban area during daytime, and the underestimation from the mechanism of Grieshop et al. (2009) is about $3.0 \mu \mathrm{g} \mathrm{m}^{-3}$ or $21 \%$ on average between 08:00 and 16:00 LT, within the uncertainty from the AMS measurements and PMF analysis. Glyoxal and methylglyoxal also play a role in the SOA formation and can contribute at most $9.6 \%$ of the observed SOA mass in the urban area when the simulated glyoxal is in agreement with the measurements. The contribution of glyoxal and methylglyoxal help to reduce the underestimation between 08:00 and 16:00 LT in the non-traditional model without the $\mathrm{OH}$ feedback, and the gap is reduced to $0.87 \mu \mathrm{g} \mathrm{m}^{-3}$ or $6.0 \%$ on average between 08:00 and 16:00 LT. It is noteworthy that there are large uncertainties of the SOA formation from glyoxal and methylglyoxal due to the uncertainty of the irreversible uptake coefficient of glyoxal and methylglyoxal on aerosol surfaces. The aging of the A-SVOC and the transport of background SOA also play an important role in the SOA evaluation.

Considering the uncertainties from measurements, emissions, meteorological conditions, aging of the SVOC and IVOC, and contributions from background transport, the non-traditional SOA model is able to close the gap in SOA mass between measurements and models.

\section{Supplementary material related to this article is available online at: http://www.atmos-chem-phys.net/11/3789/2011/ acp-11-3789-2011-supplement.pdf.}

Acknowledgements. We are indebted to the large number of people involved in the MILAGRO field campaign as well as those involved in long-term air quality monitoring and the emissions inventory in the Mexico City metropolitan area, which made this study possible, in particular, we would like to thank Jose Jimenez for making the PMF data available that we use in model comparisons. This work was supported by the US National Science Foundation's Atmospheric Chemistry Program (ATM-0528227 and ATM-0810931) and the Molina Center for Energy and the Environment. Guohui Li is a Molina Fellow at MIT. Acknowledgment is also made to the National Center for Atmospheric Research, which is sponsored by the National Science Foundation, for the computing time used in this research. The FORTH effort was supported by the European Union and the 7th Framework Programme under the project MEGAPOLI (Grant agreement no.: 212520).

Edited by: M. Gauss

\section{References}

Aiken, A. C., Salcedo, D., Cubison, M. J., Huffman, J. A., DeCarlo, P. F., Ulbrich, I. M., Docherty, K. S., Sueper, D., Kimmel, J. R., Worsnop, D. R., Trimborn, A., Northway, M., Stone, E. A., Schauer, J. J., Volkamer, R. M., Fortner, E., de Foy, B., Wang, J., Laskin, A., Shutthanandan, V., Zheng, J., Zhang, R., Gaffney, J., Marley, N. A., Paredes-Miranda, G., Arnott, W. P., Molina, L. T., Sosa, G., and Jimenez, J. L.: Mexico City aerosol analysis during MILAGRO using high resolution aerosol mass spectrometry at the urban supersite (T0) - Part 1: Fine particle composition and organic source apportionment, Atmos. Chem. Phys., 9, 66336653, doi:10.5194/acp-9-6633-2009, 2009.

Atkinson, R. and Arey, J.: Atmospheric degradation of volatile organic compounds, Chem. Rev., 103, 4605-4638, 2003.

Barsanti, K. C. and Pankow, J. F.: Thermodynamics of the formation of atmospheric organic particulate matter by accretion reactions - 2. Dialdehydes, methylglyoxal, and diketones, Atmos. Environ., 39, 6597-6607, 2005.

Bei, N., de Foy, B., Lei, W., Zavala, M., and Molina, L. T.: Using 3DVAR data assimilation system to improve ozone simulations in the Mexico City basin, Atmos. Chem. Phys., 8, 7353-7366, doi:10.5194/acp-8-7353-2008, 2008.

Bei, N., Lei, W., Zavala, M., and Molina, L. T.: Ozone predictabilities due to meteorological uncertainties in the Mexico City basin using ensemble forecasts, Atmos. Chem. Phys., 10, 6295-6309, doi:10.5194/acp-10-6295-2010, 2010.

Binkowski, F. S. and Roselle S. J.: Models-3 Community Multiscale Air Quality (CMAQ) model aerosol component: 1. Model description, J. Geophys. Res., 108(D6), 4183, doi:10.1029/2001JD001409, 2003.

Borbon, A., Fontainea, H., Veillerotb, M., Locogea, N., Gallooa, J. C., and Guillermoa, R.: An investigation into the traffic-related fraction of isoprene at an urban location, Atmos. Environ., 35, 3749-3760, 2001. 
Carlton, A. G., Turpin, B. J., Lim, H.-J., Altieri, K. E., and Seitzinger, S.: Link between isoprene and secondary organic aerosol (SOA): pyruvic acid oxidation yields low volatility organic acids in clouds, Geophys. Res. Lett., 33, L06822, doi:10.1029/2005GL025374, 2006.

Carlton, A. G., Turpin, B. J., Altieri, K. E., Seitzinger, S., Reff, A., Lin, H.-J., and, Ervens, B.: Atmospheric oxalic acid and SOA production from glyoxal: results of aqueous photooxidation experiments, Atmos. Environ., 41, 7588-7602, 2007.

Chen, F. and Dudhia, J.: Coupling an advanced land-surface/hydrology model with the Penn State/NCARMM5modelingsystem. Part I: Model description and implementation, Mon. Weather Rev., 129, 569-585, 2001.

Davidson, C. I., Phalen, R. F., and Solomon, P. A.: Airborne particulate matter and human health: A review, Aerosol. Sci. Technol., 39, 737-749, 2005.

Dudhia, J.: Numerical study of convection observed during the winter monsoon experiment using a mesoscale two-dimensional model, J. Atmos. Sci., 46, 3077-3107, 1989.

Dzepina, K., Volkamer, R. M., Madronich, S., Tulet, P., Ulbrich, I. M., Zhang, Q., Cappa, C. D., Ziemann, P. J., and Jimenez, J. L.: Evaluation of new secondary organic aerosol models for a case study in Mexico City, Atmos. Chem. Phys., 9, 5681-5709, 2009, http://www.atmos-chem-phys.net/9/5681/2009/.

de Foy, B., Fast, J. D., Paech, S. J., Phillips, D., Walters, J. T., Coulter, R. L., Martin, T. J., Pekour, M. S., Shaw, W. J., Kastendeuch, P. P., Marley, N. A., Retama, A., and Molina, L. T.: Basinscale wind transport during the MILAGRO field campaign and comparison to climatology using cluster analysis, Atmos. Chem. Phys., 8, 1209-1224, doi:10.5194/acp-8-1209-2008, 2008.

de Haan, D., Corrigan, A., Smith, K., Stroik, D., Turley, J., Lee, F., Tolbert, M., Jimenez, J., and Cordova, K., Organic aerosolforming reactions of glyoxal with amino acids, Environ. Sci. Technol., 43, 2818-2824, 2009.

de Gouw, J. A., Welsh-Bon, D., Warneke, C., Kuster, W. C., Alexander, L., Baker, A. K., Beyersdorf, A. J., Blake, D. R., Canagaratna, M., Celada, A. T., Huey, L. G., Junkermann, W., Onasch, T. B., Salcido, A., Sjostedt, S. J., Sullivan, A. P., Tanner, D. J., Vargas, O., Weber, R. J., Worsnop, D. R., Yu, X. Y., and Zaveri, R.: Emission and chemistry of organic carbon in the gas and aerosol phase at a sub-urban site near Mexico City in March 2006 during the MILAGRO study, Atmos. Chem. Phys., 9, 3425-3442, doi:10.5194/acp-9-3425-2009, 2009.

DeCarlo, P. F., Dunlea, E. J., Kimmel, J. R., Aiken, A. C., Sueper, D., Crounse, J., Wennberg, P. O., Emmons, L., Shinozuka, Y., Clarke, A., Zhou, J., Tomlinson, J., Collins, D. R., Knapp, D., Weinheimer, A. J., Montzka, D. D., Campos, T., and Jimenez, J. L.: Fast airborne aerosol size and chemistry measurements above Mexico City and Central Mexico during the MILAGRO campaign, Atmos. Chem. Phys., 8, 4027-4048, doi:10.5194/acp8-4027-2008, 2008.

Donahue, N. M., Robinson, A. L., Stanier, C. O., and Pandis, S. N.: Coupled partitioning, dilution, and chemical aging of semivolatile organics, Environ. Sci. Technol., 40, 2635-2643, 2006.

Fast, J., Aiken, A. C., Allan, J., Alexander, L., Campos, T., Canagaratna, M. R., Chapman, E., DeCarlo, P. F., de Foy, B., Gaffney, J., de Gouw, J., Doran, J. C., Emmons, L., Hodzic, A., Hern- don, S. C., Huey, G., Jayne, J. T., Jimenez, J. L., Kleinman, L., Kuster, W., Marley, N., Russell, L., Ochoa, C., Onasch, T. B., Pekour, M., Song, C., Ulbrich, I. M., Warneke, C., WelshBon, D., Wiedinmyer, C., Worsnop, D. R., Yu, X.-Y., and Zaveri, R.: Evaluating simulated primary anthropogenic and biomass burning organic aerosols during MILAGRO: implications for assessing treatments of secondary organic aerosols, Atmos. Chem. Phys., 9, 6191-6215, doi:10.5194/acp-9-6191-2009, 2009.

Fu, T.-M., Jacob, D. J., and Heald, C. L.: Aqueous-phase reactive uptake of dicarbonyls as a source of organic aerosol over eastern North America, Atmos. Environ., 43, 1814-1822, 2009.

George, I. J. and Abbatt, J. P. D.: Chemical evolution of secondary organic aerosol from $\mathrm{OH}$-initiated heterogeneous oxidation, Atmos. Chem. Phys., 10, 5551-5563, doi:10.5194/acp-10-55512010, 2010.

Grieshop, A. P., Logue, J. M., Donahue, N. M., and Robinson, A. L.: Laboratory investigation of photochemical oxidation of organic aerosol from wood fires 1: measurement and simulation of organic aerosol evolution, Atmos. Chem. Phys., 9, 1263-1277, doi:10.5194/acp-9-1263-2009, 2009.

Hallquist, M., Wenger, J. C., Baltensperger, U., Rudich, Y., Simpson, D., Claeys, M., Dommen, J., Donahue, N. M., George, C., Goldstein, A. H., Hamilton, J. F., Herrmann, H., Hoffmann, T., Iinuma, Y., Jang, M., Jenkin, M. E., Jimenez, J. L., Kiendler-Scharr, A., Maenhaut, W., McFiggans, G., Mentel, Th. F., Monod, A., Prévôt, A. S. H., Seinfeld, J. H., Surratt, J. D., Szmigielski, R., and Wildt, J.: The formation, properties and impact of secondary organic aerosol: current and emerging issues, Atmos. Chem. Phys., 9, 5155-5236, doi:10.5194/acp-95155-2009, 2009.

Harrison, R. M. and Yin, J.: Particulate matter in the atmosphere: which particle properties are important for its effects on health?, Sci. Total Environ., 249, 85-101, 2000.

Hildebrandt, L., Donahue, N. M., and Pandis, S. N.: High formation of secondary organic aerosol from the photo-oxidation of toluene, Atmos. Chem. Phys., 9, 2973-2986, doi:10.5194/acp-92973-2009, 2009.

Hodzic, A., Jimenez, J. L., Madronich, S., Aiken, A. C., Bessagnet, B., Curci, G., Fast, J., Lamarque, J.-F., Onasch, T. B., Roux, G., Schauer, J. J., Stone, E. A., and Ulbrich, I. M.: Modeling organic aerosols during MILAGRO: importance of biogenic secondary organic aerosols, Atmos. Chem. Phys., 9, 6949-6981, doi:10.5194/acp-9-6949-2009, 2009.

Hodzic, A., Jimenez, J. L., Madronich, S., Canagaratna, M. R., DeCarlo, P. F., Kleinman, L., and Fast, J.: Modeling organic aerosols in a megacity: potential contribution of semi-volatile and intermediate volatility primary organic compounds to secondary organic aerosol formation, Atmos. Chem. Phys., 10, 5491-5514, doi:10.5194/acp-10-5491-2010, 2010.

Horowitz, L. W., Waters, S., Mauzerall, D. L., Emmons, L. K., Rasch, P. J., Tie, X., Lamarque, J.-F. Schultz, M. G., Tyndall, G. S., Orlando, J. J., and Brasseur, G. P.: A global simulation of tropospheric ozone and related tracers: Description and evaluation of MOZART, version 2, J. Geophys. Res., 108(D24), 4784, doi:10.1029/2002JD002853, 2003.

Hoyle, C. R., Boy, M., Donahue, N. M., Fry, J. L., Glasius, M., Guenther, A., Hallar, A. G., Huff Hartz, K., Petters, M. D., Petäjä, T., Rosenoern, T., and Sullivan, A. P.: A review of the anthropogenic influence on biogenic secondary organic aerosol, At- 
mos. Chem. Phys., 11, 321-343, doi:10.5194/acp-11-321-2011, 2011.

Jimenez, J. L., Jayne, J. T., Shi, Q., Kolb, C. E., Worsnop, D. R., Yourshaw, I., Seinfeld, J. H., Flagan, R. C., Zhang, X., Smith, K. A., Morris, J. W., and Davidovits, P.: Ambient aerosol sampling using the Aerodyne Aerosol Mass Spectrometer, J. Geophys. Res., 108, 8425, doi:10.1029/2001JD001213, 2003.

Jimenez, J. L., Canagaratna, M. R., Donahue, N. M., Prevot, A. S. H., Zhang, Q., Kroll, J. H., DeCarlo, P. F., Allan, J. D., Coe, H., Ng, N. L., Aiken, A. C., Docherty, K. S., Ulbrich, I. M., Grieshop, A. P., Robinson, A. L., Duplissy, J. Smith, J. D., Wilson, K. R., Lanz, V. A., Hueglin, C., Sun, Y. L., Tian, J., Laaksonen, A., Raatikainen, T., Rautiainen, J., Vaattovaara, P., Ehn, M., Kulmala, M., Tomlinson, J. M., Collins, D. R., Cubison, M. J., Dunlea, E. J., Huffman, J. A., Onasch, T. B, Alfarra, M. R., Williams, P. I., Bower, K., Kondo, Y., Schneider, J., Drewnick, F., Borrmann, S., Weimer, S., Demerjian, K., Salcedo, D., Cottrell, L., Griffin, R., Takami, A., Miyoshi, T., Hatakeyama, S., Shimono, A., Sun, J. Y., Zhang, Y. M., Dzepina, K., Kimmel, J. R., Sueper, D., Jayne, J. T., Herndon, S. C., Trimborn, A. M., Williams, L. R., Wood, E. C., Middlebrook, A. M., Kolb, C. E., Baltensperger, U., and Worsnop, D. R.: Evolution of Organic aerosols in the atmosphere, Science, 326, 1525-1529, 2009.

Koo, B. Y., Ansari, A. S., and Pandis, S. N.: Integrated approaches to modeling the organic and inorganic atmospheric aerosol components, Atmos. Environ., 37, 4757-4768, 2003.

Kroll, J. H. and Seinfeld, J. H.: Chemistry of secondary organic aerosol: Formation and evolution of low-volatility organics in the atmosphere, Atmos. Environ., 42, 3593-3624, 2008.

Kulmala, M., Laaksonen, A., and Pirjola, L.: Parameterizations for sulfuric acid/water nucleation rates, J. Geophys. Res., 103(D7), 8301-8307, 1998.

Lane, T. E., Donahue, N. M., and Pandis, S. N.: Simulating secondary organic aerosol formation using the volatility basis-set approach in a chemical transport model, Atmos. Environ., 42, 7439-7451, 2008a.

Lane, T. E., Donahue, N. M., and Pandis, S. N.: Effect of $\mathrm{NO}_{\mathrm{x}}$ on secondary organic aerosol concentrations, Environ. Sci. Technol., 42, 6022-6027, 2008b.

Lei, W., de Foy, B., Zavala, M., Volkamer, R., and Molina, L. T.: Characterizing ozone production in the Mexico City Metropolitan Area: a case study using a chemical transport model, Atmos. Chem. Phys., 7, 1347-1366, doi:10.5194/acp-7-1347-2007, 2007.

Lelieveld, J., Butler, T. M., Crowley, J. N., Dillon, T. J., Fischer, H., Ganzeveld, L., Harder, H., Lawrence, M. G., Martinez, M., Taraborrelli, D., and Williams, J.: Atmospheric oxidation capacity sustained by a tropical forest, Nature, 452, 737-740, 2008.

Li, G., Zhang, R., Fan, J., and Tie, X.: Impacts of black carbon aerosol on photolysis and ozone, J. Geophys. Res., 110, D23206, doi:10.1029/2005JD005898, 2005.

Li, G., Zhang, R., Fan, J., and Tie, X.: Impacts of biogenic emissions on photochemical ozone production in Houston, Texas, J. Geophys. Res., 112, D10309, doi:10.1029/2006JD007924, 2007.

Li, G., Lei, W., Zavala, M., Volkamer, R., Dusanter, S., Stevens, P., and Molina, L. T.: Impacts of HONO sources on the photochemistry in Mexico City during the MCMA-2006/MILAGO Campaign, Atmos. Chem. Phys., 10, 6551-6567, doi:10.5194/acp10-6551-2010, 2010.
Li, S., Matthews, J., and Sinha, A.: Atmospheric hydroxyl radical production from electronically excited $\mathrm{NO}_{2}$ and $\mathrm{H}_{2} \mathrm{O}$, Science, 319, 1657-1660, 2008.

Liggio, J., Li, S.-M., and McLaren, R.: Reactive uptake of glyoxal by particulate matter, J. Geophys. Res., 110, D10304, doi:10.1029/2004JD005113, 2005.

Lin Y.-L., Farley, R. D., and Orville, H. D.: Bulk parameterization of the snow field in a cloud model, J. Appl. Meteorol., 22, 10651092, 1983.

Mlawer, E. J., Taubman, S. J., Brown, P. D., Iacono, M. J., and Clough, S. A.: Radiative transfer for inhomogeneous atmosphere: RRTM, a validated correlated-k model for the long-wave J. Geophys. Res., 102(D14), 16663-16682, 1997.

Molina, L. T. and Molina, M. J.: Air Quality in the Mexico Megacity: An Integrated Assessment, Kluwer Academic Publishers: Dordrecht, The Netherlands, 384 pp., 2002.

Molina, L. T., Kolb, C. E., de Foy, B., Lamb, B. K., Brune, W. H., Jimenez, J. L., Ramos-Villegas, R., Sarmiento, J., ParamoFigueroa, V. H., Cardenas, B., Gutierrez-Avedoy, V., and Molina, M. J.: Air quality in North America's most populous city overview of the MCMA-2003 campaign, Atmos. Chem. Phys., 7, 2447-2473, doi:10.5194/acp-7-2447-2007, 2007.

Molina, L. T., Madronich, S., Gaffney, J. S., Apel, E., de Foy, B., Fast, J., Ferrare, R., Herndon, S., Jimenez, J. L., Lamb, B., Osornio-Vargas, A. R., Russell, P., Schauer, J. J., Stevens, P. S., Volkamer, R., and Zavala, M.: An overview of the MILAGRO 2006 Campaign: Mexico City emissions and their transport and transformation, Atmos. Chem. Phys., 10, 8697-8760, doi:10.5194/acp-10-8697-2010, 2010.

Murphy, B. N. and Pandis, S. N.: Simulating the formation of semivolatile primary and secondary aerosol in a regional chemical transport model, Environ. Sci. Technol., 43, 4722-4728, 2009.

Ng, N. L., Kroll, J. H., Keywood, M. D., Bahreini, R., Varutbangkul, V., Flagan, R. C., and Seinfeld, J. H.: Contribution of first-versus second-generation products to secondary organic aerosols formed in the oxidation of biogenic hydrocarbons, Environ. Sci. Technol., 40, 2283-2297, 2006.

Ng, N. L., Kroll, J. H., Chan, A. W. H., Chhabra, P. S., Flagan, R. C., and Seinfeld, J. H.: Secondary organic aerosol formation from m-xylene, toluene, and benzene, Atmos. Chem. Phys., 7, 3909-3922, doi:10.5194/acp-7-3909-2007, 2007.

Noh, Y., Cheon, W. G., and Raasch, S.: The improvement of the Kprofile model for the PBL using LES. Preprints, Int. Workshop of Next Generation NWP Models, Seoul, South Korea, Laboratory for Atmospheric Modeling Research, 65-66, 2001.

Odum, J. R., Hoffman, T., Bowman, F., Collins, D., Flagan, R. C., and Seinfeld, J. H.: Gas/particle partitioning and secondary organic aerosol yields, Environ. Sci. Technol., 30, 2580-2585, 1996.

Pankow, J. F.: An absorption model of gas/particle partitioning involved in the formation of secondary organic aerosol, Atmos. Environ., 28, 189-193, 1994.

Paasonen, P., Nieminen, T., Asmi, E., Manninen, H. E., Petäjä, T., Plass-Dülmer, C., Flentje, H., Birmili, W., Wiedensohler, A., Hõrrak, U., Metzger, A., Hamed, A., Laaksonen, A., Facchini, M. C., Kerminen, V.-M., and Kulmala, M.: On the roles of sulphuric acid and low-volatility organic vapours in the initial steps of atmospheric new particle formation, Atmos. Chem. Phys., 10, 
11223-11242, doi:10.5194/acp-10-11223-2010, 2010.

Penner, J. E., Andreae, M. O., Annegarn, H., Barrie, L., Feichter, J., Hegg, D., Jayaraman, A., Leaitch, R., Murphy, D., Nganga, J., and Pitari, G.: Aerosols, their direct and indirect effects, in: Climate Change 2001: The Scientific Basis. Contributions of Working Group I to the Third Assessment Report of the Intergovernmental Panel on Climate Change, edited by: Houghton, J. T., Ding, Y., Griggs, D. J., Noguer, M., van der Linden, P. J., Dai, X., Maskell K., and Johnson, C. A., Cambridge University Press, Cambridge, UK, and New York, NY, USA, 289-348, 2001.

Pope III, C. A. and Dockery, D. W.: Health effects of fine particulate air pollution: Liens that connect, J. Air. Waste Manage, 56, 709$742,2006$.

Robinson, A. L., Donahue, N. M., Shrivastava, M. K.,Weitkamp, E. A., Sage, A. M., Grieshop, A. P., Lane, T. E., Pandis, S. N., and Pierce, J. R.: Rethinking organic aerosols: semivolatile emissions and photochemical aging, Science, 315, 1259-1262, 2007.

Sareen, N., Schwier, A. N., Shapiro, E. L., Mitroo, D., and McNeill, V. F.: Secondary organic material formed by methylglyoxal in aqueous aerosol mimics, Atmos. Chem. Phys., 10, 997-1016, doi:10.5194/acp-10-997-2010, 2010.

Schell, B., Ackermann, I. J., Hass, H., Binkowski, F. S., and Ebel, A.: Modeling the formation of secondary organic aerosol within a comprehensive air quality modeling system, J. Geophys. Res., 106, 28275-28293, 2001.

Shrivastava, M. K., Lane, T. E., Donahue, N. M., Pandis, S. N., and Robinson, A. L.: Effects of gas-particle partitioning and aging of primary emissions on urban and regional organic aerosol concentrations, J. Geophys. Res., 113, D18301, doi:10.1029/2007JD009735, 2008.

Song, J., Lei, W., Bei, N., Zavala, M., de Foy, B., Volkamer, R., Cardenas, B., Zheng, J., Zhang, R., and Molina, L. T.: Ozone response to emission changes: a modeling study during the MCMA-2006/MILAGRO Campaign, Atmos. Chem. Phys., 10, 3827-3846, doi:10.5194/acp-10-3827-2010, 2010.

Stanier, C. O., Donahue, N. M., and Pandis, S. N.: Parameterization of secondary organic aerosol mass fraction from smog chamber data, Atmos. Environ., 42, 2276-2299, 2008.

Tie, X., Madronich, S., Walters, S., Zhang, R., Rasch, P., and Collins, W.: Effect of clouds on photolysis and oxidants in the troposphere, J. Geophys. Res., 108(D20), 4642, doi:10.1029/2003JD003659, 2003.

Tsimpidi, A. P., Karydis, V. A., Zavala, M., Lei, W., Molina, L., Ulbrich, I. M., Jimenez, J. L., and Pandis, S. N.: Evaluation of the volatility basis-set approach for the simulation of organic aerosol formation in the Mexico City metropolitan area, Atmos. Chem. Phys., 10, 525-546, doi:10.5194/acp-10-525-2010, 2010.

Volkamer, R., Jimenez, J. L., San Martini, F., Dzepina, K., Zhang, Q., Salcedo, D., Molina, L. T., Worsnop, D. R., and Molina, M. J.: Secondary organic aerosol formation from anthropogenic air pollution: rapid and higher than expected, Geophys. Res. Lett., 33, L17811, doi:10.1029/2006GL026899, 2006.
Volkamer, R., San Martini, F., Molina, L. T., Salcedo, D., Jimenez, J. L., and Molina, M. J.: A Missing Sink for Gas-Phase Glyoxal in Mexico City: Formation of Secondary Organic Aerosol, Geophys. Res. Lett., 34, L19807, doi:10.1029/2007GL030752, 2007.

Wesely, M. L.: Parameterization of surface resistance to gaseous dry deposition in regional-scale numerical models, Atmos. Environ., 23, 1293-1304, 1989.

Zhang, Q., Jimenez, J. L., Canagaratna, M. R., Allan, J. D., Coe, H., Ulbrich, I., Alfarra, M. R., Takami, A., Middlebrook, A. M., Sun, Y. L., Dzepina, K., Dunlea, E., Docherty, K., DeCarlo, P. F., Salcedo, D., Onasch, T., Jayne, J. T., Miyoshi, T., Shimono, A., Hatakeyama, S., Takegawa, N., Kondo, Y., Schneider, J., Drewnick, F., Borrmann, S., Weimer, S., Demerjian, K., Williams, P, Bower, K., Bahreini, R., Cottrell, L., Griffin, R. J., Rautiainen, J., Sun, J. Y., Zhang, Y. M., and Worsnop, D. R.: Ubiquity and dominance of oxygenated species in organic aerosols in anthropogenically-influenced Northern Hemisphere midlatitudes, Geophys. Res. Lett., 34, L13801, doi:13810.12029/2007GL029979, 2007.

Zhang, R., Suh, I., Zhao, J., Zhang, D., Fortner, E. C., Tie, X., Molina, L. T., and Molina, M. J.: Atmospheric new particle formation enhanced by organic acids, Science, 304, 1487-1490, 2004.

Zhang, R., Li, G., Fan, J., Wu, D. L., and Molina, M. J.: Intensification of Pacific storm track linked to Asian pollution, P. Natl. Acad. Sci., USA, 104, 5295-5299, doi:10.1073/pnas.0700618104, 2007.

Zhang, Y., Dubey, M. K., Olsen, S. C., Zheng, J., and Zhang, R.: Comparisons of WRF/Chem simulations in Mexico City with ground-based RAMA measurements during the 2006-MILAGRO, Atmos. Chem. Phys., 9, 3777-3798, doi:10.5194/acp-9-3777-2009, 2009.

Zhang, Y., Liu, P., Queen, A., Misenis, C., Pun, B., Seigneur, C., and $\mathrm{Wu}, \mathrm{S}$. Y.: A comprehensive performance evaluation of MM5-CMAQ for the summer 1999 Southern Oxidants Study episode. Part II: gas and aerosol predictions, Atmos. Environ., 40(26), 4839-4855, 2006.

Zhao, J., Levitt, N. P., Zhang, R. Y., and Chen, J. M.: Heterogeneous reactions of methylglyoxal in acidic media: implications for secondary organic aerosol formation, Environ. Sci. Technol., 40, 7682-7687, 2006.

Zheng, J., Zhang, R., Fortner, E. C., Volkamer, R. M., Molina, L., Aiken, A. C., Jimenez, J. L., Gaeggeler, K., Dommen, J., Dusanter, S., Stevens, P. S., and Tie, X.: Measurements of $\mathrm{HNO}_{3}$ and $\mathrm{N}_{2} \mathrm{O}_{5}$ using ion drift-chemical ionization mass spectrometry during the MILAGRO/MCMA-2006 campaign, Atmos. Chem. Phys., 8, 6823-6838, doi:10.5194/acp-8-6823-2008, 2008. 